\title{
CINE CLEPTÓMANO: SHAME (2011) DE STEVE MCQUEEN Y LA INTERTEXTUALIDAD
}

\author{
Kleptomaniac Cinema: Shame (2011) by Steve McQueen and Intertextuality \\ Manuel Antonio Díaz Gito ${ }^{a}$ \\ Universidad de Cádiz \\ DOI: $10.15366 /$ secuencias2020.51.006
}

\begin{abstract}
RESUMEN
El objetivo de este trabajo es analizar, según la metodología del semiólogo Gérard Genette, las relaciones transtextuales localizables en Shame (2011), película dirigida por el director británico Steve McQueen. Se identifican y analizan una serie de casos de alusiones intertextuales que conectarían el filme de McQueen no solo con otros de la historia del cine, sino también con las más grandes firmas del arte moderno. La superposición de diferentes láminas textuales y artísticas convierte a Shame en un valioso palimpsesto transtextual que proyecta su propio significado a partir de la suma de las significaciones de todos sus referentes subyacentes: en otras palabras, convierte a Shame en un buen testimonio de «cine cleptómano».
\end{abstract}

Palabras clave: transtextualidad, intertextualidad, Gérard Genette, Shame, Steve McQueen, cine cleptómano

\begin{abstract}
The aim of this paper is to analyse the transtextual features of Steve McQueen's film Shame (2011), according to the methodology of the literary theorist Gerard Genette. A series of intertextual references in McQueen's film has been identified and analysed; these allusions would connect Shame with other movies from the history of cinema and with the work of some of the greatest painters of the $2 \mathrm{O}^{\text {th }}$ Century. As a result, the film becomes a meaningful transtextual palimpsest which provides its own meaning from the combination of meanings of its underlying texts. In other words, Shame becomes a good example of «Kleptomaniac Cinema».
\end{abstract}

Keywords: Transtextuality, Intertextuality, Gérard Genette, Shame, Steve McQueen, Kleptomaniac Cinema

[a] Manuel Antonio Díaz Gito es Profesor Titular del Departamento de Filología Clásica de la Universidad de Cádiz. Entre sus ámbitos de investigación se encuentran los estudios de tradición clásica y su impacto en la literatura y en el arte. En esta última área relativa al arte ha publicado varios artículos sobre la recepción clásica en la pintura holandesa del Siglo de Oro con especial atención a la obra del pintor de Leiden Jan Steen o en la ópera de asunto mitológico Daphne (1938), de Richard Strauss, sobre libreto de Josef Gregor. El estudio presente se integra en una serie de tres trabajos sobre Shame (2011), de Steve McQueen, que se han desarrollado de manera autónoma a partir del primero de ellos, que ofrecía un análisis de la película como un relato architextual de catábasis o descenso al infierno. Proyecto de Investigación de la DGICYT FFI201790831-REDT Red de Excelencia Europa Renascens: Biblioteca Digital de Humanismo y Tradición Clásica II (España y Portugal). E-mail: manuel.diazgito@uca.es 
It's not where you take things fromit's where you take them to (atribuido a Jean-Luc Godard) ${ }^{1}$

Entre su primer largometraje, aclamado por la crítica, Hunger (2008), y la oscarizada Doce años de esclavitud (Twelve Years a Slave, 2013), el cineasta británico Steve McQueen planteaba en su segunda película, titulada Shame (2011), un drama intimista y un tanto claustrofóbico a partir de un guion propio escrito en colaboración con Abi Morgan². La historia, protagonizada por Brandon Sullivan (interpretado por Michael Fassbender), un atractivo profesional de Nueva York víctima de una autodestructiva adicción al sexo, gira en torno a la difícil relación que establece con su vulnerable hermana Sissy (Carey Mulligan) cuando las circunstancias los llevan a convivir íntimamente en el apartamento de él.

Tras haber explorado en un primer ensayo las posibilidades de significación de Shame derivadas de su interpretación como un relato architextual de raíz mítica de bajada a los Infiernos ${ }^{3}$, en una segunda fase me he propuesto abordar el análisis de las relaciones transtextuales localizables en la película de McQueen haciendo uso del análisis del discurso de autores postestructuralistas, fundamentalmente del semiólogo francés Gérard Genette ${ }^{4}$.

A partir de las premisas teóricas del estructuralista ruso Mijail Bajtín (dialogismo), redefinidas, como se sabe, en la década de los sesenta por Julia Kristeva en su concepto de intertextualidad, Gérard Genette fue más allá al enunciar su concepto más abarcador de transtextualidad, que definió como la «trascendencia textual del escrito, todo lo que pone al mismo en relación manifiesta o secreta con otros textos» ${ }^{5}$. Tras distinguir y definir cinco tipos o grados de trascendencia textual - de menor a mayor grado de implicación habla de intertextualidad, paratextualidad, metatextualidad, hipertextualidad y architextualidad-, Genette focalizó su atención analítica en el que le parecía el más relevante de todos ellos, la hipertextualidad. A partir de esta fecunda obra, distintos investigadores han adoptado y adaptado la teoría de Genette también al discurso cinematográfico, suministrando el método y las herramientas de análisis de los que me he aprovechado en este trabajo ${ }^{6}$.

Por razones metodológicas, en un artículo previo concentré mi atención en sugerir y argumentar la relación de hipertextualidad detectada en Shame, mientras que mi propósito actual es analizar las diversas relaciones de intertextualidad que he creído poder identificar en el mismo filme. Pero antes de avanzar en el objetivo del presente análisis, se hace obligado por su relevancia a la hora de alcanzar las conclusiones definitivas recordar someramente las conclusiones del artículo anterior?

La hipertextualidad, según Genette, analiza las relaciones de dependencia entre un texto (el hipertexto) con otro que le precede (su hipotexto) y del que el primero se ha servido mediante su transformación, modificación o reelabo-
[1] Véase nota 43.

[2] Shame (2011), DVD, Film4, See-Saw Films, UK Film Council, UK. De aquí proceden los fotogramas que ilustran este trabajo. El guion está disponible en <http://www.imsdb.com/scripts/Shame.html> (12/05/2020).

[3] Manuel A. Díaz Gito, «El Infierno, según Steve McQueen. Shame (2011) y las Hijas de Dánao» (International Journal of the Classical Tradition, 2019). Disponible en DOI: <https:// doi.org/10.1007/s12138-01900534-2> (12/05/2020).

[4] Gérard Genette, Palimpsestos. La literatura en segundo grado (Madrid, Taurus, 1989); Graham Allen, Intertextuality (Londres/Nueva York, Routledge, 2000), pp. 95-115; Juana Marinkovich, «El análisis del discurso y la intertextualidad» (Boletín de Filología de la Universidad de Chile, $\mathrm{n} .{ }^{\circ} 37,1998-$ 1999), pp. 729-742; Amelia Sanz Cabrerizo, «La noción de intertextualidad hoy» (Revista de Literatura, n. ${ }^{\circ}$ 57, vol. 114, 1995), pp. 341-362.

[5] Genette, Palimpsestos, pp. 9-10.

[6] Robert Stam, «Introduction: The Theory and Practice of Adaptation", en Robert Stam y Alessandra Raengo (eds.), $L i-$ terature and Film. A Guide to the Theory and Practice of Film Adaptation (Malden/Oxford, Blackwell Publishing, 2005), pp. 1-52; José Antonio Pérez Bowie, "Cine e Intertextualidad», en Leer el cine. La teoría literaria en la teoría cinematográfica (Salamanca, Universidad, 2008), pp. 151-167; José Antonio Pérez Bowie, Reescrituras fílmicas. Nuevos territorios de la adaptación (Salamanca, Universidad, 2010).

[7] Manuel A. Díaz Gito, «Shame (2011) de Steve McQueen. El cine en segundo grado: la hipertextualidad» (Fotocinema. Revista de Cine y Fotografía, n. $\left.{ }^{\circ} 19,2019\right)$, pp. 213-236. 
[8] También en American Psycho asistimos a la degradación mental de un atractivo ejecutivo de Manhattan, Patrick Bateman (Christian Bale), que se pierde en el laberinto de su mente esquizofrénica hasta degenerar en un asesino en serie paranoico. Para su interpretación en clave de catábasis infernal. Juan González Etxeberria, «Epopeyas postmodernas y topografías infernales sin salida», en José Manuel Losada y Antonella Lipscomb (eds.), Myth and Emotions (Cambridge, Cambridge Scholars Publishing, 2017), pp. 279-290.

[9] Según un concepto propuesto por Pedro Javier Pardo García, «Teoría y práctica de la reescritura filmoliteraria (A propósito de las reescrituras de The Turn of the Screw)», en Pérez Bowie (ed.), Reescrituras filmicas Reescrituras filmicas. Nuevos territorios de la adaptación (Salamanca, Universidad, 2010), pp. 45-102. José Antonio Pérez Bowie, «Sobre reescritura y nociones conexas. Un estado de la cuestión», en Reescrituras filmicas. Nuevos territorios de la adaptación (Salamanca, Universidad, 2010), pp. 21-43; Pedro Javier Pardo García, «Hacia una teoría de la reflexividad fílmica. La autoconciencia de la literatura al cine», en José Antonio Pérez Bowie y Pedro Javier (eds.), Transescrituras audiovisuales (Madrid, Pigmalión, 2015), pp. 47-94; Pedro Javier Pardo García, «De la transescritura a la transmedialidad: poética de la ficción transmedial», en Antonio Gil González y Pedro Javier Pardo (eds.), Adaptación 2.o. Estudios comparados sobre intermedialidad (Binges, Éditions Orbis Tertius, 2018), pp. 41-92.

[10] A su vez, en las páginas iniciales de Palimpsestos, Genette explica la reformulación de su propio concepto previo de intertextualidad. ración. En mi opinión, el hipotexto complejo subyacente en el relato de Shame es un «texto» cinematográfico: el filme American Psycho (2000), de Mary Harron, cuyo guion es la adaptación cinematográfica de la polémica novela homónima de Bret Easton Ellis (1991).

Lo que, a mi juicio, vincula, sobre todo, la adaptación fílmica de la sátira de Ellis con la película de McQueen es la similitud del argumento centrado en el naufragio psicopático de sus protagonistas narrado en clave de descenso a los infiernos, a lo que se debe sumar una misma intencionalidad metafórica que parece apuntar a una denuncia de la deriva del capitalismo contemporáneo ${ }^{8}$. Según mi tesis, McQueen realizaría una reescritura o sobreescritura hipertextual de lo más fundamental del argumento y de las intenciones metafóricas de su hipotexto, que se podría encuadrar en lo que se ha llamado «reescritura encubierta ${ }^{9}$. Este tipo de reescritura fílmica transtextual desdibuja radicalmente los lazos de filiación con su hipotexto mediante la diversidad de transformaciones operadas, que afectan tanto a contenidos como a formas. En Shame se produciría la transposición y transformación del relato de American Psycho con vistas a la actualización y reivindicación de su contenido ideológico - esto es, la exposición y denuncia de los males del sistema capitalista neoliberal-en el umbral del siglo XXI.

\section{La intertextualidad en Shame}

Junto al hipotexto fundamental propuesto, que, según mi tesis, permea todo el relato de Shame, también bajo la superficie de la película podemos intuir, intermitentemente ahora, una variada serie de «homenajes» tanto cinematográficos como de otra diversa índole, que, trasladados a las categorías definidas por Genette, entrarían en el campo de su primera clase de transcendencia textual, la intertextualidad. Frente al concepto homónimo que veíamos acuñado a mediados de los sesenta por la semióloga Julia Kristeva, Genette prefiere entender ahora la intertextualidad como «la relación de copresencia entre dos o más textos..., es decir, como la presencia efectiva de un texto en otro» ${ }^{10}$. Este concepto comprendería un amplio espectro de relaciones entre textos que contempla desde la cita al plagio, pasando por la alusión ${ }^{11}$. El semiólogo francés considera la última de estas posibilidades, la alusión, como la menos explícita de las modalidades intertextuales; es, al mismo tiempo, la más fructífera desde el punto de vista literario y artístico.

De hecho, la práctica de la intertextualidad es generalmente aceptada como un carácter distintivo de los movimientos artísticos del siglo XX y, especialmente el cine, una vez alcanzada la época «clásica» de su historia, se presta como pocos a entregarse a cierto ensimismamiento cinéfilo ${ }^{12}$. La alusión

[11] Genette, Palimpsestos, p. 10.

[12] Sanz Cabrerizo, «La noción de intertextualidad», pp. 341-342, 358, 360. José A. Pérez Bowie, «El cine en, desde y sobre el cine: metaficción, reflexividad e intertextualidad en la pantalla» (Anthropos, n. ${ }^{\circ}$ 208, 2005), pp. 122-137; Angélica García-Manso, (Séptimo arte)². Intertextualidad fúlmica y cine (Madrid, Pigmalión, 2012). 
intertextual es, pues, una clave de identidad en gran parte del cine postmoderno ${ }^{13}$ que, en base a este rasgo, ha sido calificado por Noël Carroll como «cine de alusión»:

\begin{abstract}
Bajo el paraguas del término alusión, tal y como yo lo empleo, queda amparado un variado conjunto de prácticas que incluye las citas, la reminiscencia de géneros pasados, la reelaboración de géneros pasados, los homenajes y la recreación de escenas, secuencias, motivos narrativos, líneas de diálogo, temáticas y gestos «clásicos» de la historia del cine, especialmente a partir de cómo esa historia se cristalizó y codificó durante la década de los sesenta y principios de los setenta ${ }^{14}$.
\end{abstract}

Desde esta misma perspectiva apuntaré $-\mathrm{y}$, debido a su gran número, lo haré sucintamente- algunos de los casos de alusiones intertextuales que creo se pueden reconocer en $S h a m e^{15}$, comenzando por las citas cinéfilas, que hacen de la película de McQueen una caja de sutiles resonancias cinematográficas.

\section{Shame y Hitchcock}

En primer y más destacado lugar, la alusión de intertextualidad relacionaría Shame con la obra cinematográfica de un clásico del cine anglosajón como Alfred Hitchcock. Si entre las claves que enumerara Italo Calvino para su definición de «clásico» destacan su constante revisitación, su influencia e inagotabilidad, su capacidad para imprimir huella y modular universos, sus múltiples (re)lecturas, su particular relación con lo actual..., no hay duda de que muchas de las películas de Hitchcock entran por derecho propio en la categoría de clásicos ${ }^{16}$. El mago del suspense pasa por ser también uno de los maestros de la historia del cine que más se ha preocupado por el perfil psicológico de sus personajes, aspecto este que también resulta nuclear en el filme de McQueen.

La primera de las películas de Hitchcock que se vislumbran fugazmente entre las secuencias de Shame no puede ser otra que Psicosis (Psycho, 1960). No solo porque es ya a nivel paratextual ${ }^{17}$, es decir, desde la declaración explícita del título mismo, uno de los referentes obvios para American Psycho, la película propuesta a su vez como hipotexto de Shame ${ }^{18}$. También porque parece imposible contemplar una escena en la que una mujer - rubia y de pelo corto, desnuda, mojada - es sorprendida y atacada en la
[13] Al igual que Shame, también el relato de American Psycho - novela y película- puede ser considerado paradigmáticamente postmoderno tanto por su estilo narrativo como por su temática en torno al fenómeno «postmoderno» del serial killer.

[14] Noël Carroll, «The Future of Allusion: Hollywood in the Seventies (And beyond)» (October, n. ${ }^{\circ}$ 20, 1982), p. 52. (La traducción es mía). Robert Stam incide en esta idea al hablar de «cine replicante», cine de reciclaje. Robert Stam, Film Theory. An Introduction (Malden/Oxford, Blackwell Publishing, 2000).

[15] No por casualidad, American Psycho de Mary Harron, el hipotexto propuesto para Shame también hace amplio uso de este tipo de citas. La directora, que juega intertextualmente con la estética del cine gore y sus implicaciones culturales, muestra en el televisor de Bateman escenas de cine porno o de La matanza de Texas (The Texas Chain Saw Massacre, Tobe Hooper, 1974), el gran referente del gore. También es políticamente significativa la fugaz aparición de Reagan en un informativo televisivo.

[16] David Boyd y Richard Barton Palmer (eds.), After Hitchcock. Influence, Imitation, and Intertextuality (Austin, University of Texas Press, 2006).

[17] Según Genette, la paratextualidad comprende las relaciones entre texto y paratexto: todo lo que rodea al texto principal sin formar parte de él -título, capítulos, prefacio, ilustraciones, etc.-. Genette, Palimpsestos, p. 9.

[18] La principal transformación que había operado Bret E. Ellis sobre la película de Hitchcock es hacer a partir de un caso individual un icono generacional -definido por el adjetivo American-. El protagonista de American Psycho es un primus inter pares, líder hegemónico en un universo de poder capitalista patriarcal, mientras que el de Psycho era una rara avis, aislado en un motel de carretera y preso psicológicamente en el claustro materno. Se ha señalado la evidencia de que el apellido de Bateman, el protagonista de American Psycho, es un claro homenaje al de (Nor-man) Bates. También habría que añadir la obsesión de Bateman por las mujeres rubias, reminiscente de la de Hitchcock con respecto a sus actrices, que llegó a tal punto que se ha acuñado la expresión «Hitchcock blonde». En el guion de American Psycho las féminas de la clase alta son descritas invariablemente como «blonde, classically beautiful». Cuando Bateman contrata los servicios de prostitutas, insiste en que sean rubias («And I really can’t stress blonde enough. Blonde»). 


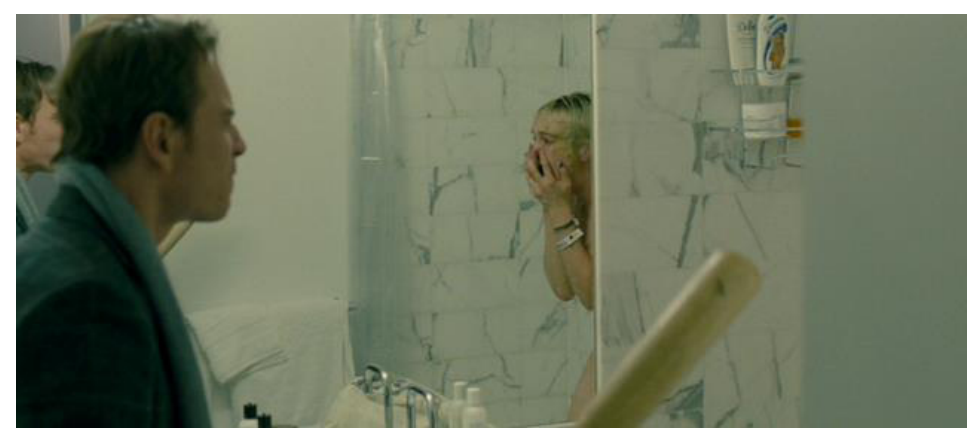

Fig. 1. Sissy atacada en el baño. Shame (Steve McQueen, 2011).

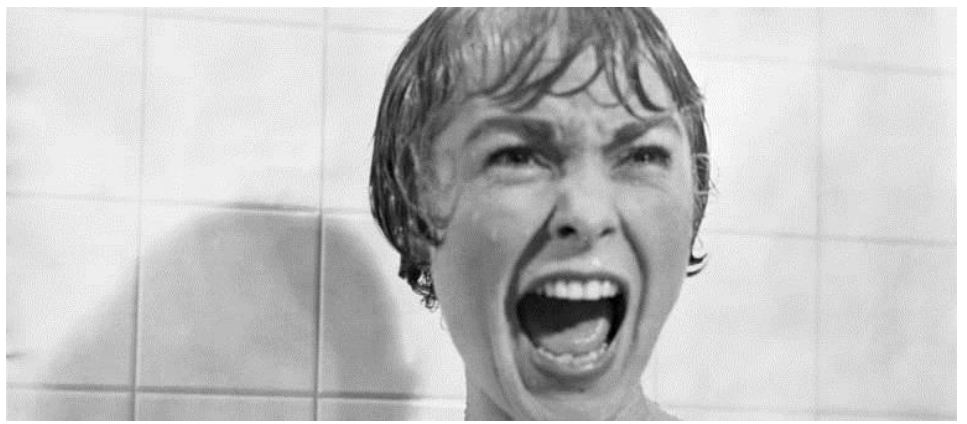

Fig. 2. Marion atacada en el baño. Psicosis (Psycho, Alfred Hitchcock, 1960). ducha por un hombre armado sin rememorar, aunque sea subliminalmente, el indeleble pasaje de Psicosis [Figs. $\begin{array}{lll}\text { y } & 2\end{array}{ }^{19}$. El encuadre elegido por McQueen, que deja ver la imagen duplicada de Sullivan en el espejo del baño, podría ser una pista en función metacinematográfica del carácter intertextual de esta escena en tácito homenaje a un referente del cine clásico de todos los tiempos. Además, la composición circular de la trama relacionaría este primer encontronazo de los dos hermanos en el baño del apartamento con su último encuentro: entonces Brandon volverá a descubrir a su hermana en el baño, esta vez tirada en el suelo en medio de un charco de sangre, una situación que, de nuevo, nos remite a la resolución de la célebre escena del primer crimen de Norman Bates.

Así, el aislamiento emocional característico de la personalidad de Brandon, reflejo aminorado de la inhumana falta de empatía de Patrick Bateman en American Psycho, podría tener una vinculación remota con la psicopatía de Norman Bates de Psycho, de quien a su vez la hereda su alter ego postmoderno, el protagonista casi homónimo (Bate-man) de la novela de Ellis.

De hecho, tanto en Psicosis, como en American Psycho y en Shame, el uso recurrente del espejo o de la imagen reflejada en espejos (o en cristales) apun-

[19] La caracterización de Carey Mulligan como Sissy - su corte y color de pelo- guarda cierto aire familiar con Marion, la primera víctima de Bates, interpretada por Janet Leigh. En Psycho y en Shame hay personajes con nombres análogos (Marion, Marianne).

[2o] Por si no bastara la abundancia de los reflejos en las superficies acristaladas que rodean el hábitat vital urbano de Brandon, su hermana actúa de incómodo espejo de su propia existencia. ta a la personalidad escindida de sus protagonistas ${ }^{20}$ que, en el tramo final de cada película, acaba rota en añicos. En el caso de Brandon, su perfil psicológico se halla escindido entre la desinhibición erótica llevada al límite de la bulimia sexual y la represión de lo emocional a modo de anorexia afectiva: cuando intenta reestructurar su vida equilibrando ambos aspectos - mediante la cita romántica con Marianne- se precipita el conflicto y el fracaso erótico. Su imagen duplicada y contrapuesta en una de las secuencias sugiere tanto su conflicto psicológico en lucha consigo mismo como la multiplicación exponencial de su libido por causa de su adicción sexual [Fig. 3].

Por otro lado, el momento poco posterior en que Brandon no se resiste a escuchar a través de la pared el «desnudo» emocional de su hermana al habla por teléfono con su exnovio podría ser reminiscente de la secuencia voyeur de 


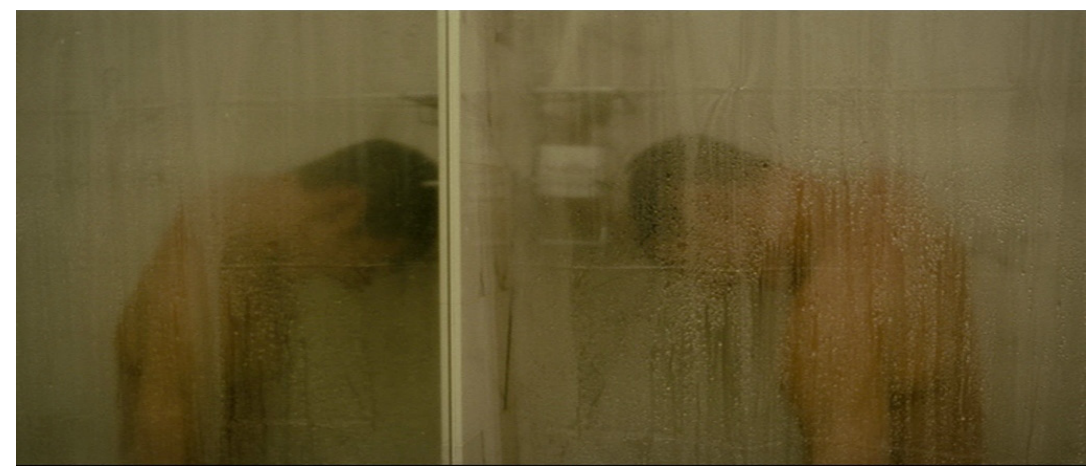

Fig. 3. Brandon en la ducha. Shame.

Norman Bates espiando a través del agujero de la pared a su inquilina mientras esta se desviste - ambas escenas se desarrollan tras el momento inicial en que la mujer se ha instalado en la vivienda [Figs. 4 y 5 ]-.

De hecho, el tema de la pulsión voyerista, que tanto interesó a Hitchcock y que tan presente está en las secuencias recién comentadas de $P$ sicosis ${ }^{21}$, no es

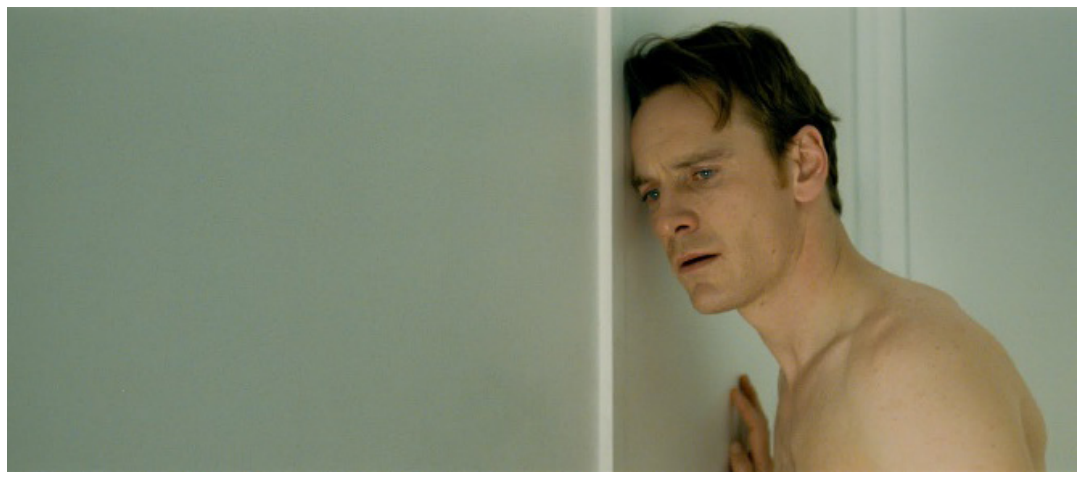

Fig. 4. Brandon espía a Sissy. Shame.

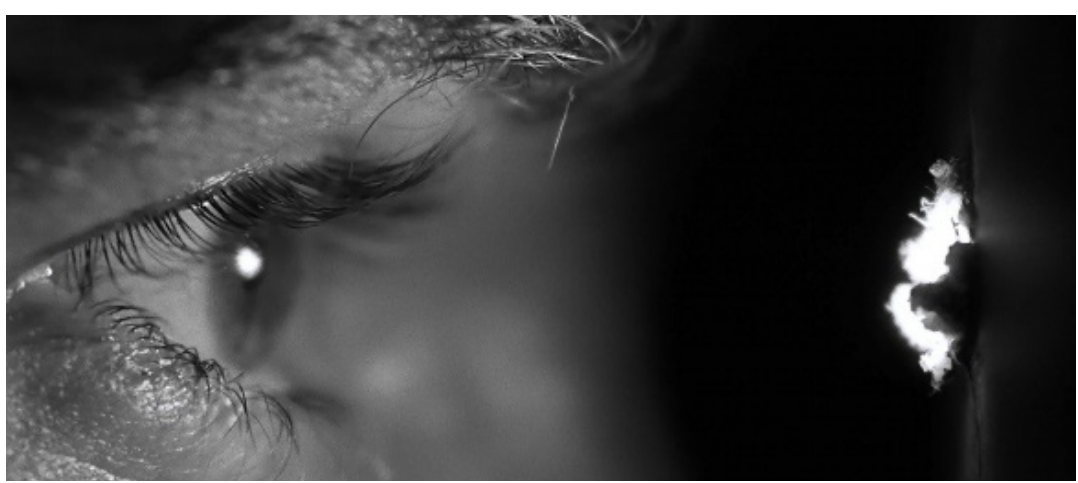

Fig. 5. Bates espía a Marion. Psicosis.

[21] Delil Hasan Sütcü, Voyeuristic Pleasure in Cinema: A study of voyeurism in Peeping Tom, Rear Window (Tesis de Máster, Aalborg, Aalborg University, 2017). Disponible en: <https://projekter.aau.dk/ projekter/files/259994358/ Full_PDF.pdf> (12/05/2020); Jesús García Requena, «Viendo mirar (La mirada y el punto de vista en el cine de Hitchcock)», en Javier Luengos (ed.), Alfred Hitchcock (Oviedo, Fundación Municipal de Cultura, 1989), pp. 148-163; Rebeca Romero Escrivá, «El universo Psycho. "La ansiedad de la influencia" en la obra de Hitchcock» (L'Atalante. Revista de estudios cinematográficos, $\mathrm{n}^{\circ}{ }^{18}$, 2014), pp. 64-70. 


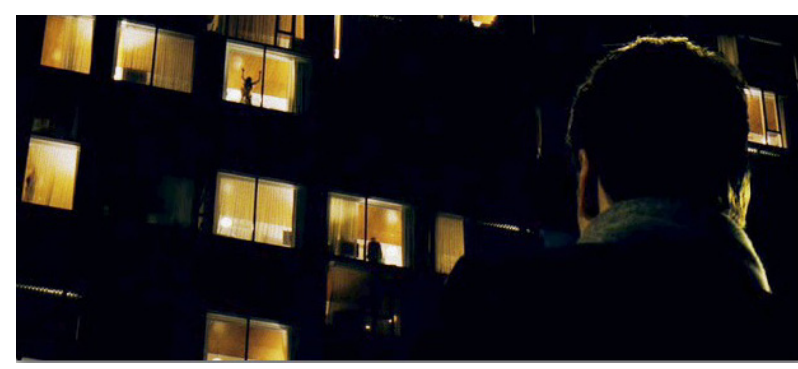

Fig. 6. Brandon, voyeur. Shame.

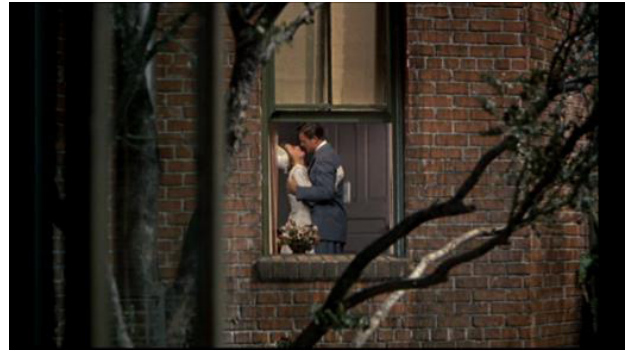

Fig. 7. Jefferies, voyeur. La ventana indiscreta (Rear Window, Alfred Hitchcock, 1954).
[22] Todas las conductas sexuales implicadas en la adicción al sexo que persiguen reducir la ansiedad y otros afectos como la vergüienza o la depresión -fantasías sexuales, masturbación compulsiva, acopio de pornografía, cibersexo, voyerismo, sexo anónimo, parejas múltiples- se nos muestran reflejadas en el carácter de Brandon. Enrique Echeburúa, «¿Existe realmente la adicción al sexo?» (Adicciones, n. ${ }^{\circ}$ 24, vol. 4, 2012), pp. 281-286.

[23] McQueen parece subrayar la evolución de lo visualmente permisible en el cine comercial en los cincuenta años que separan una película de la otra: basta comparar la ingenuidad de las escenas diurnas que se nos permite observar a través de la mirada curiosa de Jeff frente a la explicitud sexual de lo que nos hacen ver los ojos de un mirón como Brandon agazapado en la noche. Véase también Fig. 23: Brandon observa desde fuera del restaurante a Marianne que, sentada a la mesa, lo espera inquieta por su tardanza.

[24] Véase el análisis de la sociedad contemporánea que desde la metáfora del voyeur y su aplicación a las nuevas modalidades de acceso a la intimidad y al análisis artístico realiza Carolina Sanabria en $L a$ contemplación de lo íntimo. Lo audiovisual en la cultura contemporánea (Madrid, Biblioteca Nueva, 2011). un tema menor en Shame, pues se identifica con uno más de los síntomas de la sexoadicción de su protagonista ${ }^{22}$. Así, para instalar este tema en la mente $-y$ en la mirada cómplice- del espectador, al realizador le basta con mostrarnos una escena circunstancial en la que Brandon espía los fragmentos de vidas de una serie de personas asomadas a las ventanas de un hotel, escena que recrea célebres secuencias de otro de los clásicos de Hitchcock, La ventana indiscreta (Rear window, 1954), filme metacinematográfico construido sobre el puro acto morboso de observar [Figs. 6 y 7$]^{23}$.

También Shame es una película vertebrada sobre la mirada y el punto de vista de su protagonista, solo que en ella el patio de vecinos de La ventana indiscreta se ha extendido, en virtud de la cibercomunicación, a la ciudad y al mundo entero ${ }^{24}$. Al igual que ocurría en la película de Hitchcock, cuando en determinado momento el espía aficionado con prismáticos se convierte a su vez en sujeto observado desde el otro lado del patio, también en Shame, Brandon, que desde la calle ha contemplado a una pareja haciendo el amor frente al ventanal de una habitación de hotel [Fig. 6], acaba siendo el protagonista de un idéntico número sexual en el mismo hotel [Fig. 8] para contemplación del espectador-voyeur de la sala de cine.

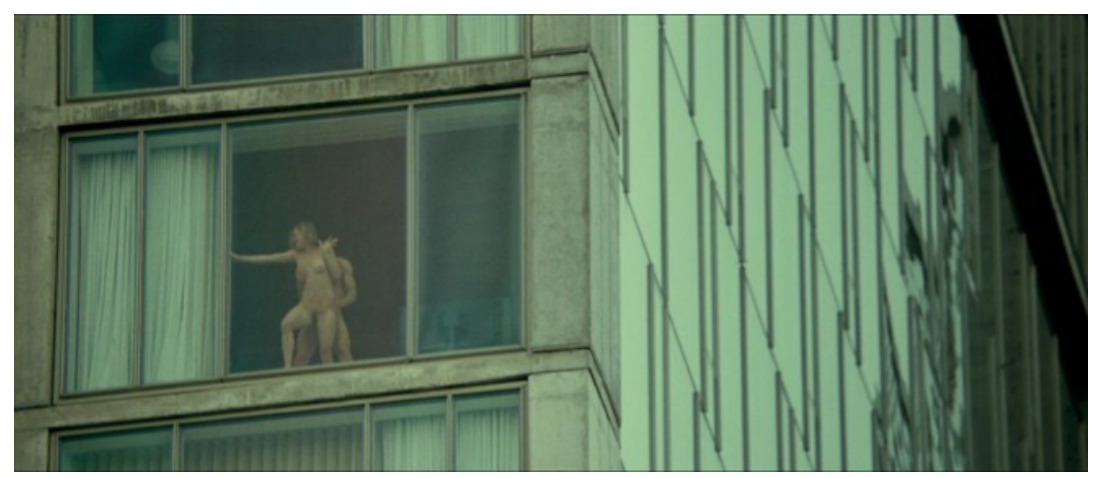

Fig. 8. Brandon exhibicionista. Shame. 
McQueen explota al máximo este juego voyerista de reflejos con el objetivo de que el espectador se sienta emocionalmente implicado en la peripecia de sus personajes [Fig. 9]. A través de acertadas estrategias cinematográficas, el realizador se complace en situarnos en la incómoda piel del voyeur, provocando que el sentimiento de vergüenza que exhibe el título de su película no ataña exclusivamente a su protagonista. Comienza por interpelarnos con la desinhibida exposición - física y emocional- de los protagonistas o con la explicitud de sus actos sexuales - con los oídos de Brandon escuchamos a través de la pared la humillante conversación telefónica de Sissy o sus ruidos mientras hace el amor con un amante ocasional; con Sissy sorprendemos a Brandon en el baño atareado en sus más íntimos manejos [Fig. 9]-.

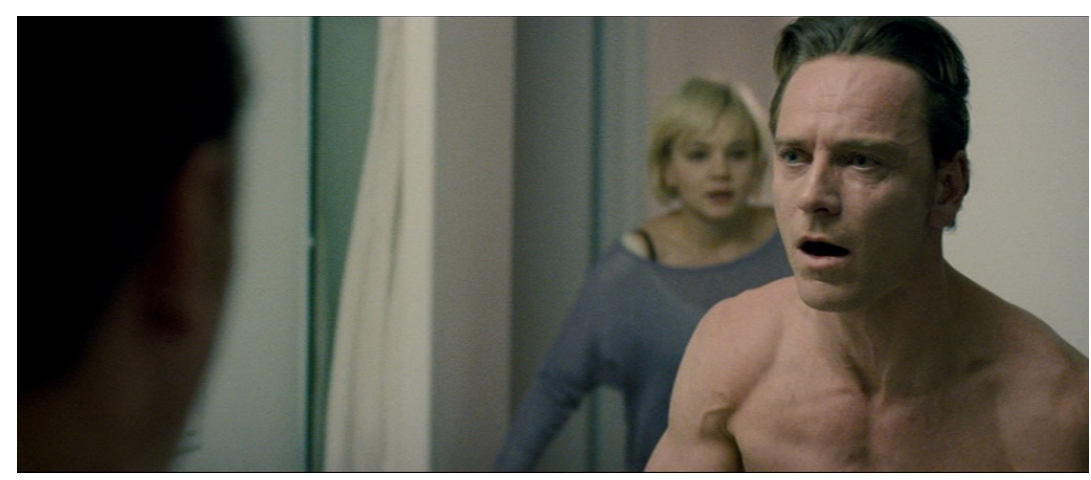

Fig. 9. Sissy sorprende a Brandon. Shame.

McQueen primeramente nos adiestra en la actitud del voyeur: mediante la mirada de Brandon aprendemos a observar furtivamente desde las sombras de la noche a la pareja exhibicionista de la ventana del hotel, asimilada a una pantalla de ordenador expendedora de porno [Fig. 6]. Luego nos deja, ya solos, observar cómplicemente a Brandon haciendo lo propio desde la misma cristalera [Fig. 8]. Otras veces, el cineasta sitúa a los personajes de espaldas a la cámara delante de una pantalla de televisión [Fig. 10] o sitúa la silueta de Brandon de espaldas y a oscuras, recortada delante de un ventanal [Fig. 25]; logra así que la perspectiva de los personajes coincida exactamente con la del espectador-voyeur en la sala de cine, que siente estar asistiendo a la discusión de una pareja en la fila delantera de asientos o estar agazapado entre la sombras de la habitación espiando la intimidad de Brandon. De este modo se acorta, se difumina la distancia entre la pantalla - del cine o (lo que es lo mismo) del ordenador ${ }^{25}$ - y la fila de butacas, entre protagonista y espectador, despertando la empatía, pero también el morbo, la complicidad, la culpa y la vergüenza de la audiencia. La «ventana abierta al mundo», metáfora clásica de la representación fílmica, es ahora, más que nunca, una ventana abierta al mundo íntimo de las personas.
[25] Téngase en cuenta que actualmente la distribución y, por tanto, la visión de las películas se hace tanto o más a través de las plataformas telemáticas que en las salas convencionales de cine, cada vez menos numerosas. 
[26] Es una pieza que no ha dejado indiferente al séptimo arte. Solo en España, más de treinta años después de haber ofrecido su particular homenaje al texto de Cocteau en una escena de La ley del deseo (Pedro Almodóvar, 1987) y de retomarlo al año siguiente como situación de partida para Mujeres al borde de un ataque de nervios (Pedro Almodóvar, 1988), se ha publicado recientemente que entre los proyectos inmediatos de Almódovar figura abordar de nuevo una adaptación del texto con Tilda Swinton. También en Mujeres al borde de un ataque de nervios hay una cita cinéfila a La ventana indiscreta, lo cual no es de extrañar en quien sin duda es el más «cleptómano» de nuestros directores.

[27] En el mismo sentido opera el estribillo de la canción «I Want Your Love» de Chic que Sissy ha puesto a sonar en el apartamento tras acceder a él. Antes de verla en pantalla, su voz en el contestador y esta canción es lo primero que de ella se nos da a conocer.

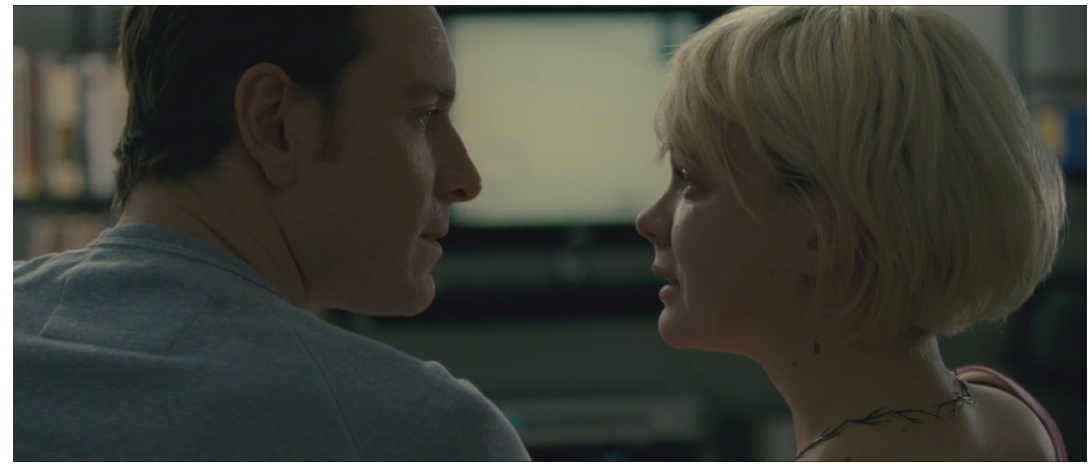

Fig. 10. Brandon y Sissy ante la pantalla del televisor. Shame.

\section{La voz humana de Cocteau}

Ya fuera del imaginario hitchcockiano, otras situaciones parecen recrear otros momentos memorables de la historia del cine. En el breve monólogo desesperado de Sissy, enganchada al teléfono suplicando a un amante - del que no oímos sus palabras- que no la abandone, no cuesta reconocer un velado homenaje a un texto clásico de la dramaturgia gala, La voz humana (La voix humaine, 1930) de Jean Cocteau, que fue encarnado magistralmente en el cine por Anna Magnani (El amor, L'amore, Roberto Rossellini, 1948) entre otras enormes actrices -Jeanne Moreau, Ingrid Bergman, Simone Signoret- y adaptado en numerosas ocasiones a distintos formatos artísticos ${ }^{26}$. Como vimos en la escena de la ducha, la imagen duplicada de Sissy en el reflejo de la ventana invita a pensar de nuevo que, metacinematográficamente, la propia escena es trasunto y tributo de la escena previa del filme italiano [Figs. 11 y 12].

Con tal sugerencia y una extraordinaria economía de medios, McQueen perfila ya desde estas primeras secuencias de Sissy su carácter dependiente, vulnerable y necesitado de la comunicación que posibilita la voz humana, una personalidad opuesta a la de su hermano, hermético e incapaz hasta el momento final de aflorar sus sentimientos ${ }^{27}$. De hecho, lo primero que conocemos de

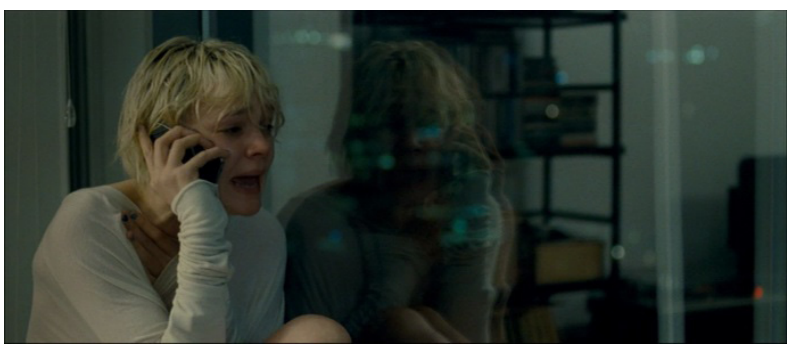

Fig. 11. «La voz humana». Shame.

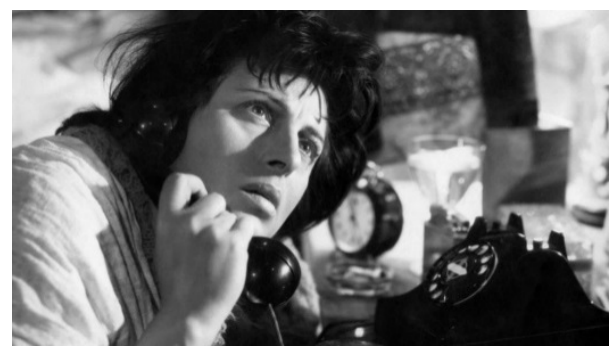

Fig. 12. «La voz humana». El amor (L'amore, Roberto Rossellini, 1948). 
Sissy es su voz insistente, reiterativa e infructuosamente anclada en el contestador automático de Brandon que nunca devuelve las llamadas, y - a excepción de una desfallecida palabra de ligero reproche en la cama del hospital- casi lo último que escuchamos de ella es, de nuevo, otra grabación desesperada e inatendida en el contestador automático de su inasequible hermano. El teléfono, en manos de Sissy, es un objeto paradójico: más que vehículo de comunicación es soporte y testimonio de la imposibilidad del contacto humano.

\section{Metropolis, de Fritz Lang, y Blade Runner, de Ridley Scott}

El propio guion de Shame, en una ocasión, recurre a la cita cinematográfica explícita para evocar de la manera más expeditiva un ambiente determinado. Lo hace cuando invoca dos celébres referentes cinematográficos para describir como «un cruce entre Metropolis y Blade Runner» la atmósfera que debe sugerir el club nocturno donde canta $\operatorname{Sissy}^{28}$. La referencia a estos dos clásicos de la ciencia ficción no puede ser gratuita. Metropolis (Fritz Lang, 1927) describe un mundo antagónico separado en dos clases, una élite privilegiada cuyo hábitat es la superficie de la gran urbe y sus rascacielos - no muy alejada de la aristocracia financiera descrita en American Psycho- frente a un proletariado esclavizado que pena bajo tierra - reminiscente del inframundo del suburbano que se nos muestra reiteradamente en Shame-. La imagen de éxito y egocentrismo asociada a Brandon y a su jefe David, un infiel impenitente, tanto en su estancia en este establecimiento como en la otra escena del grupo de empresa en otro club nocturno, es una obvia referencia al universo heteropatriarcal de los amos del mundo descrito en American Psycho. Por su parte, la angustiosa atmósfera de Blade Runner (Ridley Scott, 1982) en cierto modo aparece replicada en la fotografía gris-azulada de Shame, fría, brumosa y oscura y en las calles sucias, llenas de bolsas negras de basura, por donde deambulan los personajes, todo ello en las antípodas de la imagen glamurosa de Nueva York que el cine ha instalado en nuestro imaginario. Por otro lado, el club donde actúa Sissy, descrito en el guion como un lugar «que va más allá de la idea de elegancia de David», un lugar «para morirse» - «it is to die for»-, sería el equivalente de uno de los exclusivos clubs de Manhattan de American Psycho, quizás el inalcanzable Dorsia, al que solo los muy elegidos logran acceder - de hecho, el único que lo consigue es víctima de la envidia asesina de Bateman, convirtiéndose así literalmente en un lugar «to die for»-.

\section{New York, New York de Martin Scorsese}

En este club futurista, el Boom Boom Room, asistimos en uno de los pasajes más emotivos de Shame, a la conmovedora interpretación del estándar musical «New York, New York» en la voz de Sissy, lo que ya de por sí es una cita intertextual. La actriz Carey Mulligan acomete una versión lastimosa, en clave de blues sugerido por la letra — «These little town blues | Are melting away»-,
[28] Así lo indica la acotación del guion:

49 Int. Boom Boom Room. Night. Brandon and David enter a beautiful bar. A spectacular 180 degree view of Manhattan. The room has the most elegant decor. It is to die for: Metropolis meets Blade Runner, a glittering New York skyline to the North of the room, the grey endless black of the Hudson River to the South. It surpasses David's idea of classy. 

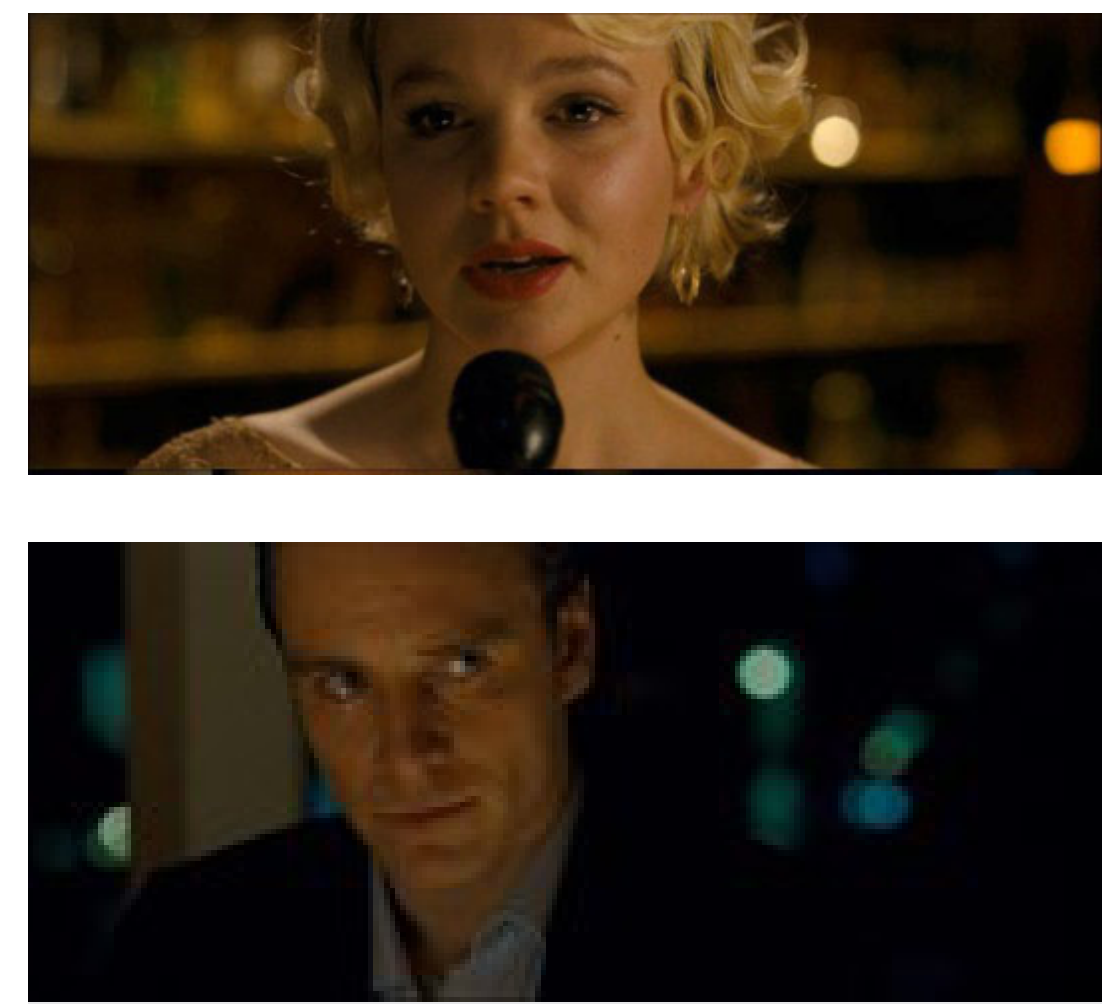

Figs. 13 y 14. «New York, New York». Shame.

que invierte el optimismo del mensaje original del tema, un himno que en las enérgicas voces de Liza Minnelli o, después, Sinatra celebraba la fe en el éxito en la ciudad-que-nunca-duerme.

La interpretación de «New York, New York» a cargo de Sissy en presencia de su hermano en este elegante club [Figs. 13 y 14] es prácticamente una recreación a base de primeros planos de su precedente cinematográfico, cuando la Minnelli impresionaba con su exitosa actuación a Robert de Niro en el momento álgido de la película homónima de Martin Scorsese (1977) [Figs. 15 y 16].

A través de la vinculación con la temática del filme del cineasta americano, McQueen introduce el tema del triunfo y el fracaso personal, un tema importante imbricado en las cuestiones planteadas por su película que aparece representado por cada uno de los dos hermanos y que, en cierta medida, hereda de su hipotexto American Psycho. Además, la versión ralentizada de Sissy, a medio camino entre el desvalimiento casi naif y el cariz sutilmente erótico, apunta

[29] $C f$. el epígrafe "El infierno, los infiernos de Brandon Sullivan”, en Díaz Gito, «El Infierno, según Steve McQueen». a una doble función narrativa. En una película donde las reminiscencias órficas abundan $^{29}$, Sissy, como si estuviera en posesión de las virtudes musicales de Orfeo, consigue lo imposible, emocionar por un momento hasta las lágrimas 

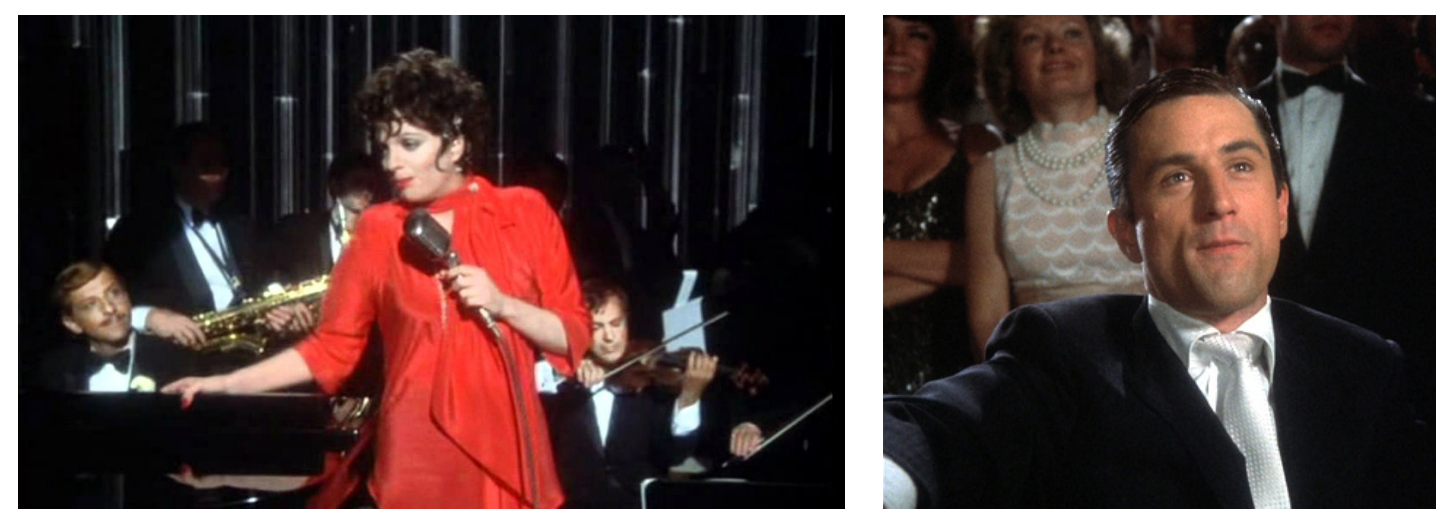

Figs. 15 y 16. «New York, New York». (New York, New York, Martin Scorsese, 1978).

a su inconmovible hermano, mientras que simultáneamente atrae por su sensualidad la atención de David, el jefe de Brandon, que será su próximo amante. A este último respecto, recordemos que la acotación del guion señalaba que este club debía sugerir la atmósfera de Metropolis: este clásico del cine mudo alemán presenta una escena en un elegante club donde la rubia protagonista celebra una sensual danza mediante la que consigue la erotización generalizada, casi por encantamiento, del público masculino presente en la sala.

\section{Gimme Shelter, de The Rolling Stones}

Nada parece carente de intención en Shame. Fijémonos en una conversación banal por las calles de la ciudad tras la cena romántica de Brandon con Marianne, su colega de trabajo. Ante la declaración de la época en que él le dice que le hubiese gustado vivir - ser un músico en los años sesenta-, ella le replica que esa época le parecía «un infierno» («it kind of seemed like hell»): añade la mujer que esa había sido su impresión tras su reciente visión en televisión del documental Gimme Shelter (Albert y David Mayles y Charlotte Zwerin, 1970) sobre los Rolling Stones. Ahora bien, en el contexto de lo que nos cuenta Shame, ¿̇podemos considerar gratuita la mención de Gimme shelter? «Refugio» es precisamente lo que Sissy «reclama» a su hermano desde su primera aparición en el apartamento. Pero es que, además, «Gimme Shelter», primer tema del álbum de los Stones de 1969 titulado Let It Bleed, comienza con unos versos que parecen describir el estado mental del propio Brandon, de quien acabaremos descubriendo que se halla necesitado de amparo no menos que su desvalida hermana: «Oh, a storm is threatening | My very life today | If I don't get some shelter | oh yeah I'm gonna fade away...». La canción acaba afirmando una idea que valdría igualmente de perfecto colofón para Shame: «I tell you love, sister, | It's just a kiss away». Que es justo la insalvable distancia que separa a los dos hermanos, la distancia que, sin embargo, tras la experiencia de Brandon en el infierno, quizás logrará sortear. 
En el tramo resolutivo de la película, Brandon descubrirá a su hermana desfallecida en el suelo del baño con las venas cortadas, justo a tiempo de salvarla de una muerte inminente impidiendo que la sangre siga brotando - lo contrario que enuncia el álbum Let it Bleed donde se integra la canción mencionada por Marianne-. En la escena posterior, Brandon, profundamente afectado, por vez primera toma la iniciativa de acercarse emocionalmente a su hermana convaleciente en la cama del hospital, rozando apenas su muñeca donde se acumulan las heridas abiertas de su reciente intento de suicido con viejas cicatrices de cortes autoinfligidos, testigos de una adolescencia de la que solo llegamos a intuir que no debió ser fácil.

\section{La música de Shame: Harry Escott frente a Hans Zimmer}

La banda sonora de Shame, firmada por Harry Escott, presenta dos de sus únicos tres temas originales, «Brandon» (8:33) y «Unravelling» (9:42), caracterizados por la inclusión inicial de elementos metronómicos parecidos a las pulsaciones de un reloj sobre una melodía reiterativa envuelta en una sección de cuerdas. No cuesta reconocerlos como dos pastiches musicales o ecos al límite del plagio de la pieza «Journey to the line» (9:22) incluida en la columna sonora compuesta por Hans Zimmer para La delgada línea roja (The Thin Red Line, Terrence Malick, 1998), una película que, como otras ambientadas en el conflicto de Vietnam, también ha sido catalogada bajo el paraguas de la catábasis infernal ${ }^{30}$. A través de su compositor Harry Escott, McQueen ni siquiera ha buscado elementos muy recónditos, pues Zimmer, uno de los grandes compositores musicales del cine contemporáneo, presenta la inclusión de estos patrones rítmicos en varias de sus partituras más recordadas, casi a modo de firma personal. La innovación de McQueen ha consistido en servirse de esa envolvente atmósfera musical para aglutinar tres secuencias fragmentadas y barajadas cronológicamente, es decir, desestructuradas por la edición del montaje, en dos momentos clave de su película: al principio, el tema «Brandon» ilustra musicalmente la presentación del personaje y las rutinas de su vida vacía antes de que la irrupción de su hermana acabe con ese frágil equilibrio de gestos repetidos; y casi al final de la película, la melodía recurrente de «Unravelling», entre lo hipnótico y lo angustioso, lo acompaña en su errático descenso al infierno, su particular «Journey to the line».

\section{Otras citas intertextuales}

[3o] Erling B. Holtsmark, «The Katabasis Theme in Modern Cinema», en Martin. M. Winkler (ed.), Classical Myth and Culture in the Cinema (Oxford, Oxford University Press, 2001), pp. 23-50.
La incursión de Brandon en territorio «comanche» en el club gay nos retrotrae al personaje de Al Pacino en una secuencia similar de otra película polémica - como Shame y, casi por los mismos motivos, como American Psycho-de los ochenta. A la caza (Cruising, de William Friedkin, 1980): en los dos casos, el personaje se adentra en ese laberinto claustrofóbico sin pertenecer propiamente a ese lugar para acabar devorado por él. En una y otra película el submundo de 
ambiente homosexual se halla caracterizado por la saturación cromática de la fotografía escénica - rojo en Shame, azul en Cruising [Figs. 17 y 18]- y es reinterpretado como lugar de reminiscencia infernal y meta del descenso al abismo de sus protagonistas. Por otro lado, en las escenas preliminar y postliminar de Shame, las de seducción de una mujer desconocida desarrolladas ambas en un vagón de metro, encontramos la inversión de los roles de depredador y presa - la mujer invasivamente seducida por Brandon en la primera escena se convierte en activa seductora en la última-, que es el tema fundamental sobre el que gira la trama de Cruising.

Cuando Brandon, en el andén subterráneo del metro, se burla de su hermana por su extravagante sombrero vintage, utiliza una expresión, «sombrero loco» («mad hat»), que conecta directamente con el personaje de Alicia de Lewis Carrol («the (Mad) Hatter»): la observación de Brandon no es gratuita,

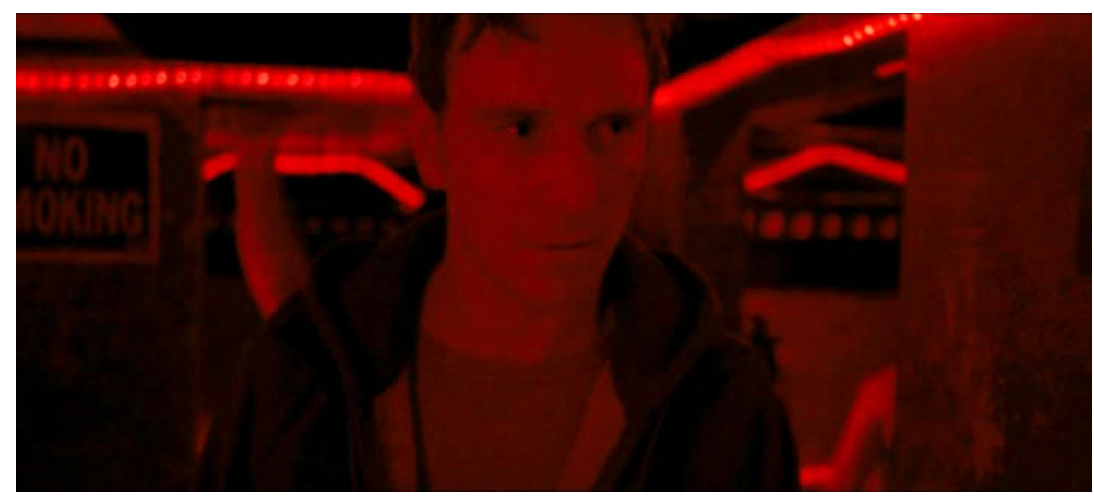

Fig. 17. Incursión en el infierno. Shame.

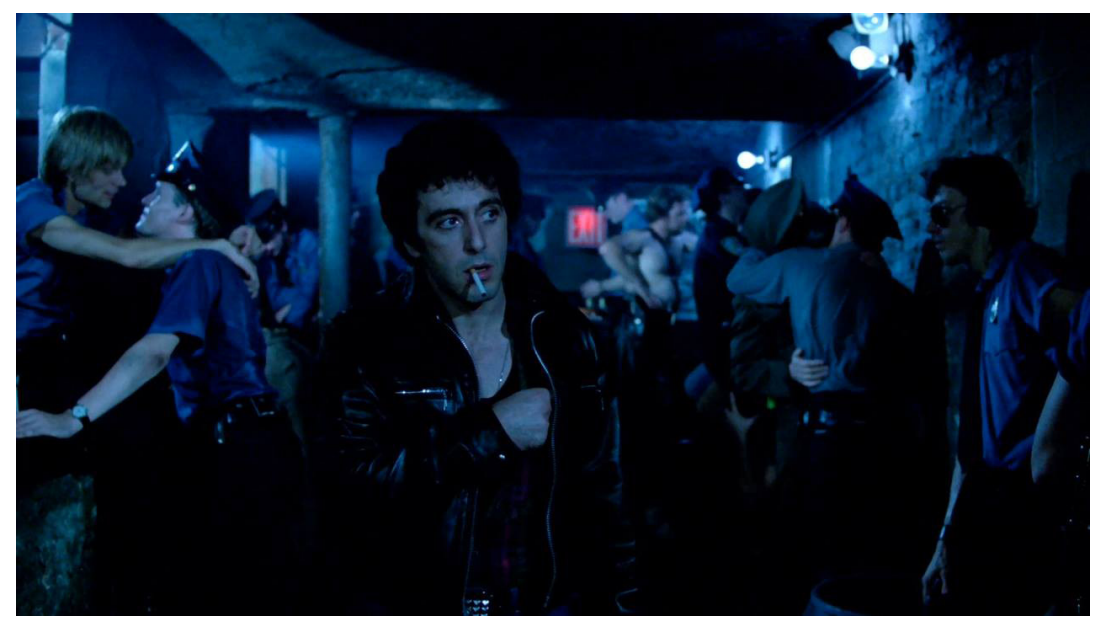

Fig. 18. Incursión en el infierno. A la caza (Cruising, William Friedkin, 1980). 
pues en ambos casos se trata de un sombrero de copa alta o chistera. No por casualidad Alicia es la protagonista de otro descenso al Inframundo sui generis, como declara el primer título que llevó el famoso cuento, Las aventuras subterráneas de Alicia (Alice's Adventures under Ground) -tampoco parece casual que McQueen sitúe la escena en cuestión en un andén de metro («underground»), en inglés británico— ${ }^{31}$. Además, el color rojo del sombrero puede ser un detalle significativo. Este color solo reaparecerá en el último tramo de la película en dos momentos clave: en el inframundo del club gay y en la sangre derramada de Sissy que acabará empapando las manos de su hermano. Esta secuencia del andén sirve para anticipar la resolución de la trama cuando Brandon rescata a su hermana cuando esta juega peligrosamente al borde de la vía: en ella el sombrero pasa de la cabeza de uno a la del otro, acentuando el común destino fatal que aguarda a los dos hermanos.

\section{Shame y el arte moderno}

[31] He defendido la interpretación del cuento de Carroll como una revisitación del tema mítico de descensus ad Inferos en una ponencia leída en Orbis Latinus. IX Congreso Internacional de la Sociedad de Estudios Latinos (Granada, 13-17/05/2019) con el título de «Psique en el País de las Maravillas. Apuleyo y Lewis Carroll», cuya redacción por escrito espero publicar en breve.

[32] Interesa a este respecto leer las páginas que Pérez Bowie dedica a «La intertextualidad pictórica» dentro de su capítulo sobre «Cine e Intertextualidad», en Leer el cine. La teoría literaria en la teoría cinematográfica (Salamanca, Universidad, 2008), pp. 151167.

[33] «Turner Prize 1999 artists: Steve McQueen», TATE, 1999. (La traducción es mía). Disponible en: <https://www.tate. org.uk/whats-on/tate-britain/ exhibition/turner-prize-1999/ turner-prize-1999-artists-steve-mcqueen> (12/05/2020).

[34] Hugh Davies y Sally Yard (eds.), Francis Bacon (Nueva York, Abbeville Press 1986), pp. 41-44.
Algunas de las reminiscencias localizables en Shame nos llevarían al ámbito del arte pictórico, especialmente, del arte moderno ${ }^{32}$. No resulta extraño en un director cuya primera formación académica fue fundamentalmente de naturaleza artística y que culminó en la Tisch School of the Arts de la New York University. La trayectoria artística de McQueen ha evolucionado a partir de la realización de cortometrajes exhibidos en espacios museísticos (1993-2007), lo que le hizo acreedor del prestigioso premio Turner 1999 en consideración a «la poesía y claridad de su visión y el alcance, intensidad emocional y economía de medios de su obra», virtudes que podría decirse también adornan a una película como Shame ${ }^{33}$. A este respecto me limitaré a esbozar unas breves pinceladas de intertextualidad dejando el mayor peso de la argumentación a la evidencia de la comparación entre las imágenes propuestas.

\subsection{Francis Bacon y las ruinas del alma.}

La deformación en movimiento de la imagen de Sullivan -concretamente, de su busto- en el escaparate del club gay donde se ha desarrollado la penúltima fase de su catábasis infernal [Fig. 19], parece pretender sugerir la angustia existencial de los retratos - bustos- expresionistas del artista británico Francis Bacon (1909-1992), caracterizados por su violenta y cruda distorsión.

Bacon era de la opinión de que para llegar a la expresión de la realidad a través del arte la única vía era la distorsión; solo a través de la distorsión se puede transformar lo que es mera apariencia en imagen ${ }^{34}$. En otras palabras, la deformación de lo epidérmico es el único acceso posible al alma de lo representado. El artista irlandés en varias ocasiones reunió sus retratos en grupos de tres (Three Studies for Self-Portrait, 1976) [Fig. 20], a veces en cuatro autorretratos alineados en vertical, como si reprodujesen el formato de la tira de instantáneas de fotomatón que le servía de modelo (Four Studies for 


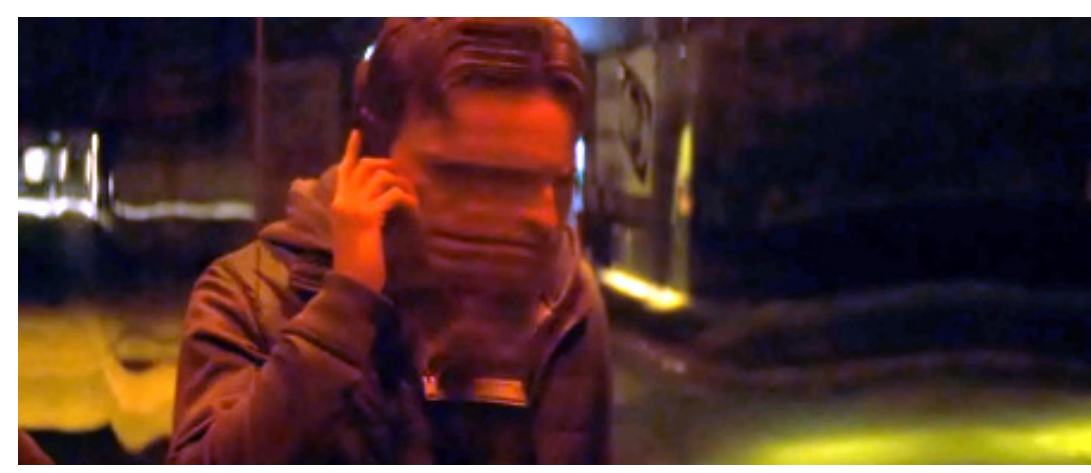

Fig. 19. Brandon. Shame.

a Self-Portrait, 1967), confiriéndoles de este modo una impresión de imagen en desarrollo. Similarmente, la imagen deformada en movimiento de Brandon también se nos muestra parcelada varias veces por las junturas de los cristales del escaparate, lo que acentúa el paralelismo con las obras de Bacon.

Incluso merece comentarse que Bacon en una ocasión se autorretrató con un ojo hinchado (Self-Portrait with Injured Eye, 1972), detalle que comparte la imagen magullada de Sullivan en el escaparate como consecuencia de la paliza recibida en el bar previamente a su incursión en el antro gay. Como se ha hecho con la pintura de Bacon $^{35}$, la herida apreciable en el rostro de Sullivan podría interpretarse como una metáfora física de la encarnizada lucha que se libra en el interior de su cuerpo, de la violencia y el sufrimiento que atenazan su mente.

En esta deformación deliberada de la belleza del actor protagonista preanunciada por la paliza ya aludida, coronada con un escupitajo lanzado a su cara y que poco más tarde acabará en el rictus extremo de su rostro consumido (imagen del alma) durante la escena del trío con las prostitutas-, McQueen parece, en línea con el ideario de Bacon, querer que nos asomemos a los estragos
[35] Frédérique Amselle, «Bacon and Freud's Self-Portraits or the Remains of the Self» (Études britanniques contemporaines, n. $\left.{ }^{\circ} 43,2012\right)$, pp. 109-122.

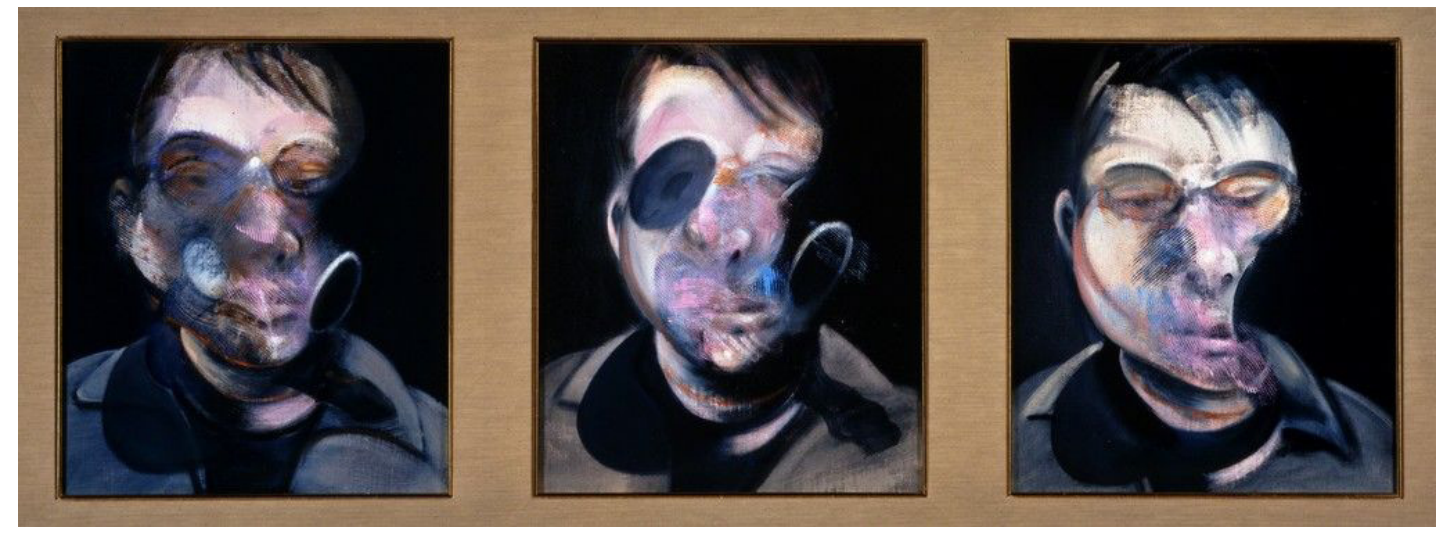

Fig. 20. Three Studies for Self-Portrait (1976), de Francis Bacon. 


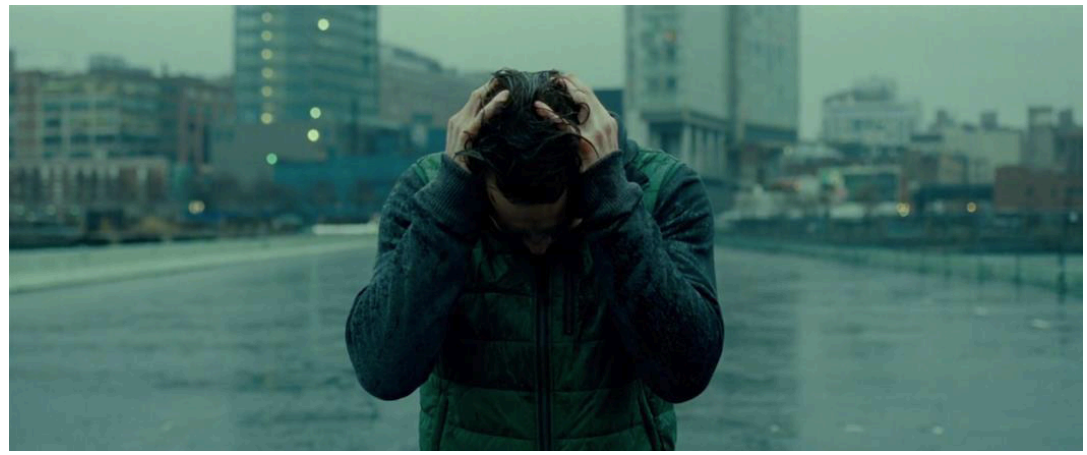

Fig. 21. El grito de Brandon. Shame.

que en el alma en descomposición de su protagonista produce su incursión por los meandros del infierno, como si por un momento se nos permitiese contemplar la imagen deteriorada en el retrato oculto de un Dorian Gray del siglo XXI.

\subsection{El grito sordo de Edvard Munch}

Tras el descubrimiento de la tentativa de suicidio de su hermana envuelta en sangre, el grito agónico de socorro de Brandon Sullivan en la escena final de catarsis de la película - su localización en el puerto del Hudson, la similar perspectiva del encuadre, la presencia erguida de las dos figuras de las torres a la espalda del personaje central, la valla de la izquierda [Fig. 21] - rememora el horror, la angustia, de El grito, de Edvard Munch (1863-1944).

Como es sabido, la obra de Munch pasa por representar la alienación y ansiedad existencial del hombre moderno: en ella destaca el color del cielo, que al volverse rojizo - como la sangre- provocaba ese descomunal grito [Fig. 22].

Conviene recordar que el ahora célebre cuadro de Munch empezó a escalar

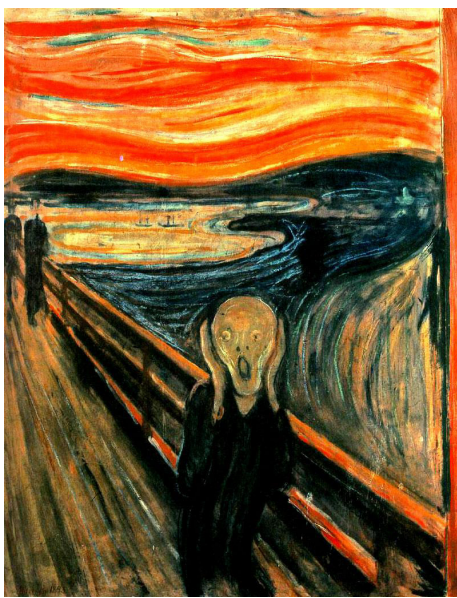

Fig. 22. El grito (1893), de Edvard Munch. la cima de su popularidad tras aparecer en marzo de 1961 en la portada de la revista Time en un número en que se destacaba su dosier dedicado a la culpa y a la ansiedad. La ansiedad es una emoción característica del mundo postmoderno, alineada junto con la confusión, el estrés, la inseguridad, la falta de arraigo y la fluidez en las relaciones humanas. En el caso de Brandon Sullivan, la ansiedad, provocada por su fracaso en el intento de retomar las riendas de su vida y por su caida libre en el pozo de la adicción al sexo y la culpa por su responsabilidad en el intento de suicidio de su hermana, tras ser repudiada y 
sentirse abandonada por él, son precisamente los motivos que generan su grito sordo en la patética escena conclusiva de Shame. El propio título de la película de McQueen alude a una emoción, la de la vergüenza, que ni los expertos se ponen de acuerdo en cómo separar de la de la culpa.

\subsection{Edward Hooper: el alma desértica en la gran ciudad}

Sin embargo, si hay un creador cuya obra parece trascender a lo largo de varias secuencias de Shame -y me atrevería a decir que a lo largo de toda la película-, ese es el artista genuinamente norteamericano y urbano Edward Hopper (1882-1967). Hopper, a lo largo de su trayectoria, hizo de Nueva York el icono por antonomasia de la moderna gran ciudad (americana) y epítome de sus contradicciones para el desarrollo de las interrelaciones humanas ${ }^{36}$. No volveré sobre el tema del voyerismo ya tratado anteriormente, sino para traer a colación las similitudes que la ensayista británica Olivia Laing encuentra entre la mirada artística característica de Hopper y la del protagonista de La ventana indiscreta de Hitchcock -al que ya he relacionado con Brandon Sullivan-. Laing señala, además, las paradojas que encierra el hecho de que, en una gran urbe como Nueva York, uno se pueda sentir absolutamente aislado en medio de la multitud o de que se pueda exponer a la mirada indiscreta, curiosa, invasiva u obscena de cualquier desconocido, incluso estando en la aparente privacidad de la propia casa, dos nociones presentes en el mundo postmoderno descrito en Shame. De hecho, lo primero que oímos - sin verlo- en la película, tras los momentos iniciales de Brandon yacente pensativo y en silencio en su cama, es el ruido del descorrer de las persianas de su dormitorio dejando entrar la luz del exterior, luz que incide sobre el título Shame de la película proyectado sobre su cama deshecha ${ }^{37}$ : una significativa metáfora de la cruda revelación de su intimidad que nos espera.

La invasión de la intimidad de Sullivan es, en efecto, una de las constantes de la película que alimentan su sentimiento de vergüenza. La amenaza contra su intimidad aparece tanto a nivel doméstico - la irrupción de Sissy en el apartamento, la escena en la que esta espía el contenido sexual del portátil de su hermano, cuando lo sorprende masturbándose en el baño o cuando se introduce de noche en su cama- como a nivel social - el «virus» pornográfico que descubren en su ordenador de empresa, su fracaso sexual con Marianne, su escena de exhibicionismo en el hotel-.

Pues bien, la composición de varias de las tomas de Shame, especialmente aquellas donde se nos permite observar a alguno de los protagonistas a través de o enfrentados a una gran ventana o en la soledad de un cuarto - a veces, de hotel- me parecen deudoras, si no del color, sí del universo, la composición y la atmósfera característicos del pintor que supo captar como nadie la soledad, el aislamiento y la incomunicación en el espacio de la gran metrópolis norteamericana [Figs. 23-30].

Hay, además, «fotografías» en Shame [Figs. 31, 32 y 33] que, sin tener un claro referente en la obra de Hopper, podrían ser consideradas como un
[36] Remito al sugerente capítulo titulado «Paredes de cristal» sobre la personalidad y la obra artística de Edward Hooper y su interrelación con la ciudad de Nueva York, en Olivia Laing, La ciudad solitaria. Aventuras en el arte de estar solo (Madrid, Capitán Swing, 2017), pp. 17-44.

[37] Tras esta, otras dos veces oímos en los momentos iniciales del film cómo Brandon descorre las persianas dejando entrar la luz en su cuarto. 


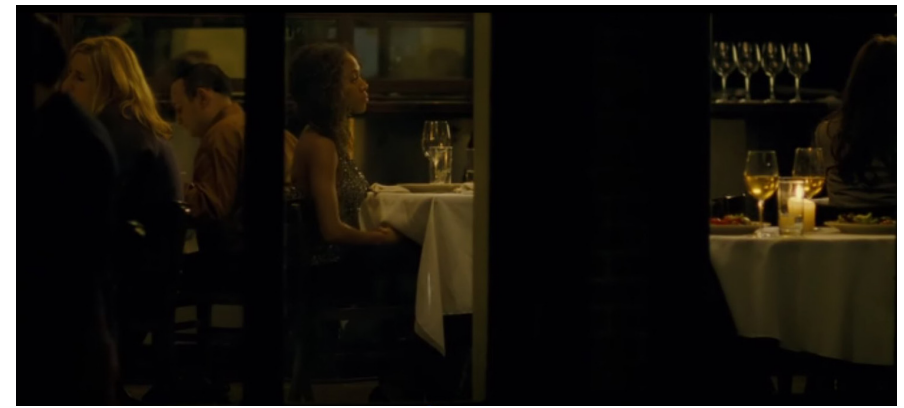

Fig. 23. Marianne en el restaurante. Shame.

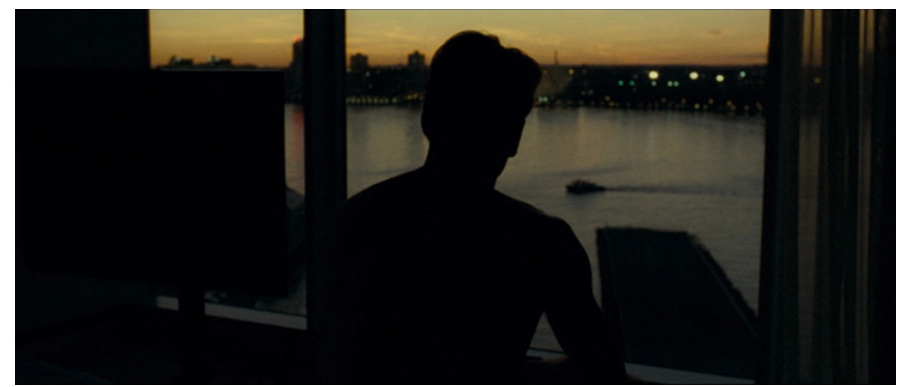

Fig. 25. Brandon en el hotel. Shame.

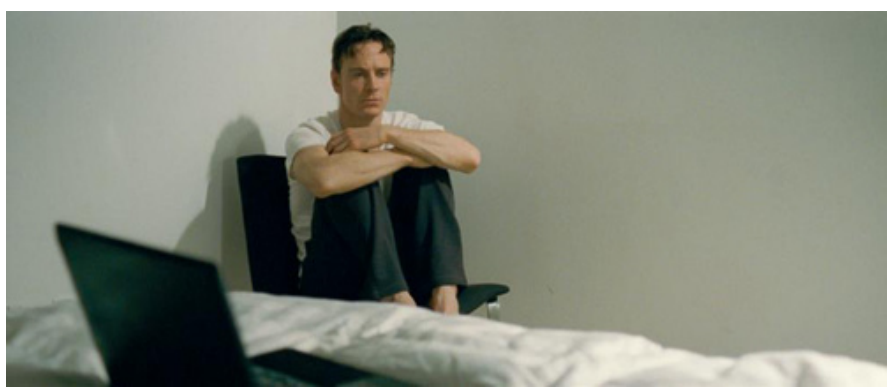

Fig. 27. Brandon en su habitación. Shame.

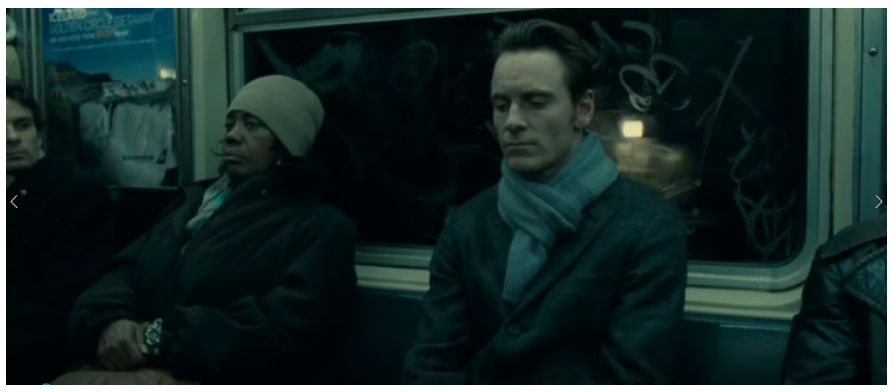

Fig. 29. Brandon en el metro. Shame.

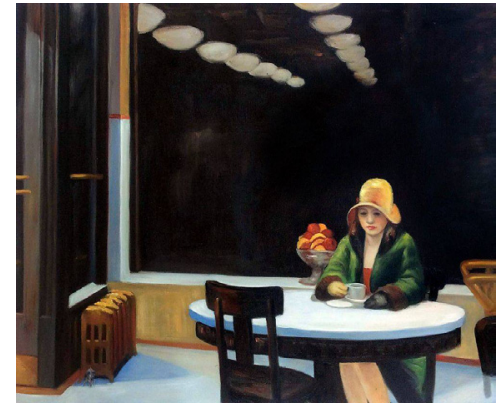

Fig. 24. Automat (1927), de Edward Hopper.

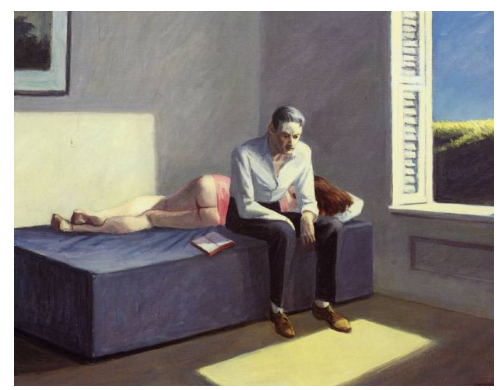

Fig. 26. Excursion into Philosophy (1959), de Edward Hopper.

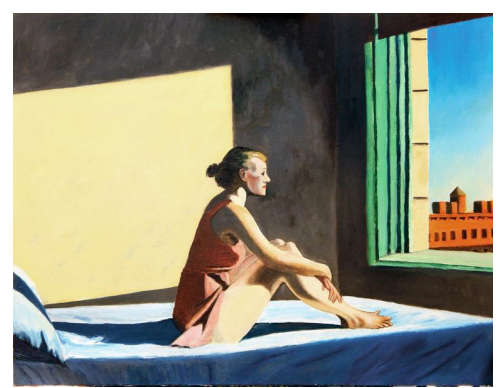

Fig. 28. Morning Sun (1952), de Edward Hopper.

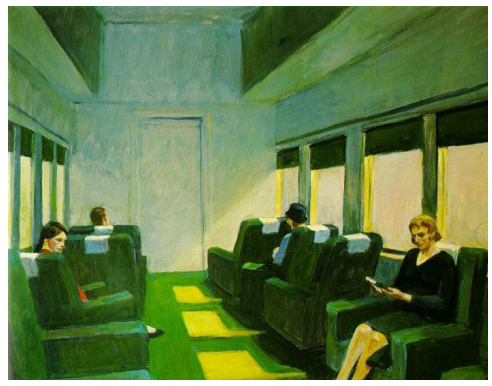

Fig. 30. Chair Car (1965), de Edward Hopper. 
tributo al espíritu del artista americano de la experiencia de la soledad en la gran ciudad, de quien

[...] Carter Foster, director del Museo Whitney, en su obra Hopper's Drawings señala que el artista reproduce rutinariamente en su pintura «determinados espacios y experiencias espaciales característicos de Nueva York que son el resultado de estar físicamente cerca de otros, pero separados de ellos por diversos factores, como movimientos, estructuras, ventanas, paredes, luz u oscuridad» ${ }^{8}$.

Palabras estas que igualmente describen el hábitat humano que retrata la película de McQueen.

De entre estas escenas, quizás la más «hopperiana» de todas ${ }^{39}$ sea aquella en la que contemplamos a Brandon en la cocina de su apartamento ab-

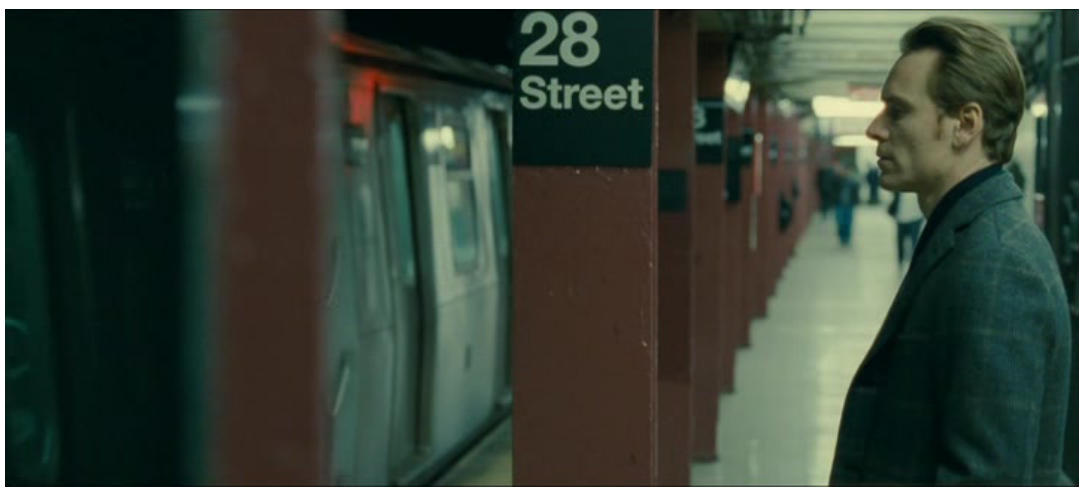

Fig. 31. Brandon en el andén del metro. Shame.

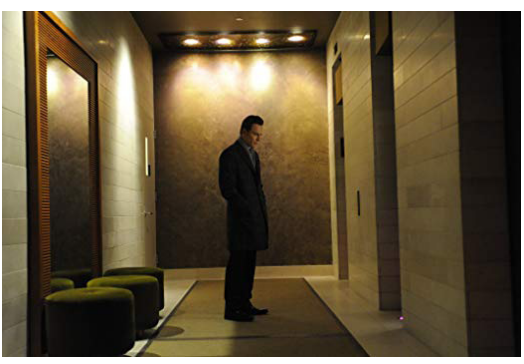

Fig. 32. Brandon ante el ascensor. Shame.

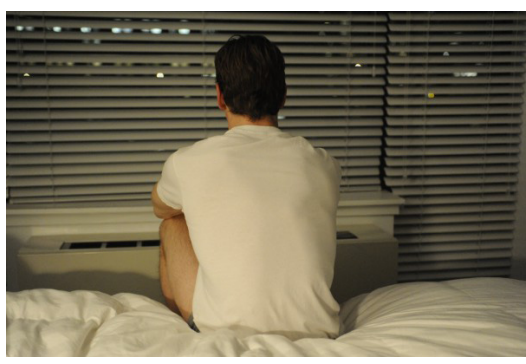

Fig. 33. Brandon en su habitación. Shame. sorto en la rutinaria y solitaria tarea de buscar contactos sexuales a través de la pantalla de su portátil; allí vemos su figura recortada sobre una ventana sin cortinas que deja asomar los característicos «ojos» de la ciudad envuelta en la oscuridad de la noche, las ventanas tantas veces representadas en la obra del pintor norteamericano [Fig. 34$]^{40}$. La perspectiva de este encuadre cinematográfico convierte al protagonista de esta escena, enfrascado en su
[38] Olivia Laing, La ciudad solitaria, p. 22.

[39] Y, a la vez, la más imposible, porque Hopper murió en 1967, escasos años antes de la irrupción de internet en la vida del hombre moderno, sin poder sospechar cómo tal innovación vino paradójicamente a revolucionar y radicalizar los problemas de (in)comunicación humana que con tanta insistencia testimonió en su obra.

[40] La autora trae a colación «la analogía entre una ventana y un ojo, tal y como sugieren su etimología y su función», mientras que una nota de la traductora Catalina Martínez Muñoz aclara el aspecto etimológico aludido: «Del latín ventus, que derivó en wind (viento) en las lenguas germánicas y en inglés en wind-eye: el ojo del viento, posteriomente window». Olivia Laing, La ciudad solitaria, p. 22. 
tantálica tarea de observador en la aparente salvaguarda de la intimidad de su hogar, en el sujeto inadvertido - o víctima- de una doble e invasiva observación: la de los «ojos» de la ciudad de «paredes de cristal», desde un lado, y la de la mirada del espectador-voyeur de la sala cinematográfica, desde el otro. Al mismo tiempo, las ventanas/pantallas encendidas de la ciudad, como los múltiples ojos que no parpadean de un Gran Hermano orwelliano — «Big Brother is watching you»-, también apuntan directamente hacia los habitantes de la sala cinematográfica, resumen y espejo del mundo. Al igual que Brandon Sullivan, quienes observamos, somos observados.

[41] Julia Kristeva, «Word, Dialogue and Novel», en Toril Moi (ed.), The Kristeva Reader (New York, Columbia University Press, 1986), p. 37. (La traduccción es mía).

[42] Como Tarantino o Almódovar, dos ejemplos evidentes en cuyas filmografías la intertextualidad juega un deliberado rol de estilo y una función (auto)reflexiva. Erik Tóth, Intertextuality in the Cinematic Production of Quentin Tarantino (Tesis de Grado, Masaryk University, 2011). Disponible en: <https://is.muni.cz/ th/m9mj2/Thesis_Final.pdf > (12/05/2020); Javier Herrera, «El cine dentro del cine en la obra de Pedro Almodóvar: pasión cinéfila y tradición barroca», en María R. Matz y Carole Salmon (eds.), How the Films of Pedro Almodovar Draw upon and Influence Spanish Society (Nueva York, The Edwin Mellen Press, 2012), pp. 115-136.

[43] Jim Jarmusch, «Things I’ve learned: Jim Jarmusch» (Moviemaker Magazine, 05/06/2013). Disponible en: <https://www. moviemaker.com/archives/ series/things_learned/jim-jarmusch-5-golden-rules-of-moviemaking/> (12/05/2020). ( $\mathrm{La}$ traducción es mía).

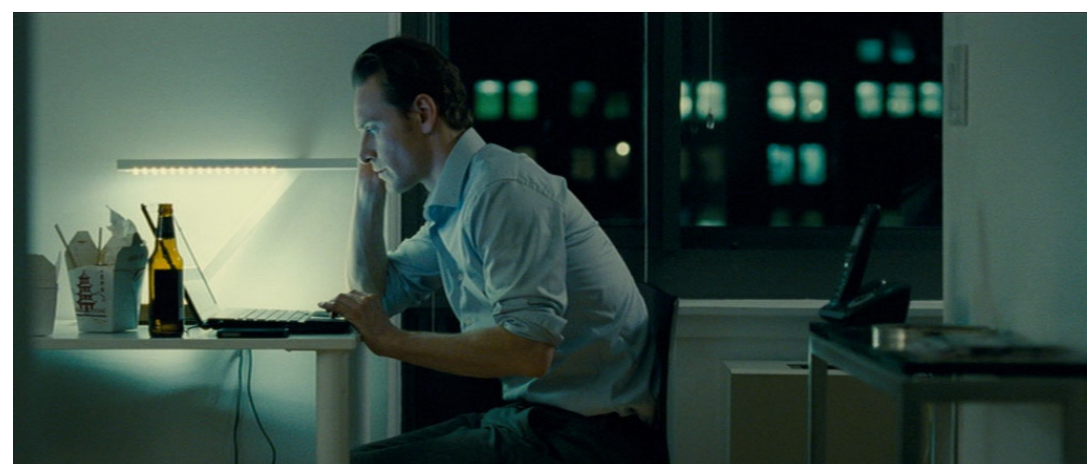

Fig. 34. Brandon ante el ordenador. Shame.

\section{Conclusiones}

En una expresión a su vez ampliamente citada y en consonancia con otras similares de otros autores posteriores al estructuralismo, Julia Kristeva afirmó que todo texto literario se construye como «un mosaico de citas» ${ }^{41}$. Siguiendo la estela de esta idea, algunos cineastas son más conscientes que otros de esta realidad $^{42}$, como Jim Jarmusch, que entre sus cinco «reglas de oro» cinematográficas propuso la siguiente como la quinta y última:

Nada es original. Roba de donde sea que aliente tu inspiración o que espolee tu imaginación. Devora viejas películas, nuevas películas, música, libros, pinturas, fotografías, poemas, sueños, conversaciones casuales, arquitectura, puentes, señales en la calle, árboles, nubes, corrientes de agua, luces y sombras. Elige para robar solo cosas de aquello que te hable directamente al corazón. Si haces esto, tu obra (y tu robo) serán auténticos. La autenticidad no tiene precio; la originalidad simplemente no existe. Y no te preocupes por ocultar tu robo - celébralo si te apetece-. En cualquier caso, recuerda siempre lo que dijo Jean-Luc Godard: «No importa de dónde tomes las cosas, importa a dónde las llevas». (Regla núm. 5) ${ }^{43}$

Considerados los argumentos desarrollados, en mi opinión, McQueen, al menos en lo que respecta a Shame, no dudaría en suscribir estas palabras de su 
colega americano. McQueen, condicionado por su propia formación artística, parece actuar como un «cleptómano» cinematográfico que no duda en atesorar e incorporar en su obra determinadas sugerencias intertextuales que le inspiran no solo grandes clásicos de la historia del cine, sino también algunos de los más influyentes pintores del siglo veinte. A este carácter cleptómano tampoco escapa - ni lo ha pretendido- mi propio trabajo, un metatexto - el tercer tipo de transtextualidad de Genette- enriquecido con ideas y citas de Gérard Genette, Noël Carroll, Julia Kristeva, Olivia Laing, Jim Jarmusch, que ha tratado de identificar y justificar estas alusiones intertextuales diseminadas -más o menos conscientemente- por McQueen entre las secuencias de su película. A este respecto quiero alinearme con la propuesta de Roland Barthes en su famoso ensayo sobre «La muerte del autor», en el sentido de que el texto, una vez producido, pasa a ser del dominio del receptor, que tiene el cometido de descifrarlo e interpretarlo, en cierta forma, de hacerlo suyo ${ }^{44}$.

En conclusión, junto a la interpretación de Shame como un relato de tradición mítica de bajada a los Infiernos, la incorporación del hipotexto propuesto (American Psycho), con su mensaje metafórico de denuncia política del capitalismo salvaje, más la suma de las referencias cruzadas de otros intertextos sugeridas en este trabajo, una vez reutilizado todo este material por McQueen para configurar su obra según sus intereses y principios artísticos y para beneficiarse así de la amplificación del significado que la incorporación de los pre-textos latentes le aporta, convierte a Shame en un rico palimpsesto transtextual. Su potencia de expresión, proyectada y aumentada a partir de la combinación de todas sus láminas textuales subyacentes, trasciende y enriquece la interpretación lineal de lo que se nos cuenta epidérmicamente en un primer término. Parafraseando la fórmula de Genette, Shame resulta así un perfecto testimonio de «cine en segundo grado», y McQueen, como el protagonista de su película, se nos muestra en cierto modo arrastrado también por una pulsión «cleptómana» que le impulsa a enriquecer su obra mediante la cita, el homenaje o la sugerencia de grandes autores del cine y del arte moderno.

\section{Bibliografía}

ALLEN, Graham, Intertextuality (Londres/Nueva York, Routledge, 2000).

Amselle, Frédérique, «Bacon and Freud's Self-Portraits or the Remains of the Self» (Études britanniques contemporaines, n. ${ }^{0}$ 43, 2012), pp. 109-122. Disponible en: <https://journals.openedition.org/ebc/1326> (12/o5/2020). DOI: 10.4000/ ebc. 1326

BARTHES, Roland, «The Death of the Author» (Aspen: The Magazine in a Box, n. ${ }^{\circ} 5-6$, 1967). Disponible en: <http://www.ubu.com/aspen/aspen5and6/index.html> (12/05/2020).

Boyd, David y Barton PaLmer, Richard (eds.), After Hitchcock. Influence, Imitation, and Intertextuality (Austin, University of Texas Press, 2006).

CARroll, Noël, «The Future of Allusion: Hollywood in the Seventies (And beyond)» (October, n. ${ }^{\circ}$ 20, 1982), pp. 51-81. DOI:10.2307/778606
[44] Roland Barthes, «The Death of the Author» (Aspen: The Magazine in a Box, n. $\left.{ }^{\circ} 5-6,1967\right)$. Disponible en: $<$ http://www.ubu.com/aspen/aspen5and6/index.html> (12/05/2020). 
DAvies, Hugh y Yard, Sally (eds.), Francis Bacon (Nueva York, Abbeville Press, 1986).

Díaz Gito, Manuel Antonio, «El Infierno, según Steve McQueen. Shame (2011) y las Hijas de Dánao» (International Journal of the Classical Tradition, 2019). Disponible en DOI: <https://doi.org/10.1007/s12138-019-00534-2> (12/05/2020).

-, «Shame (2011) de Steve McQueen. El cine en segundo grado: la hipertextualidad» (Fotocinema. Revista de Cine y Fotografía, n. ${ }^{0}$ 19, 2019), pp. 213-236. Disponible en DOI: <http://dx.doi.org/10.24310/Fotocinema.2019.v2i19.6653> (12/05/2020).

ECHEburúa, Enrique, «¿Existe realmente la adicción al sexo?» (Adicciones, n. ${ }^{0}$ 24, vol. 4, 2012), pp. 281-286.

García-Manso, Angélica, (Séptimo arte)². Intertextualidad filmica y cine (Madrid, Pigmalión, 2012).

Genetre, Gérard, Palimpsestos. La literatura en segundo grado (Madrid, Taurus, 1989).

GonzÁlez EtXeberRia, Juan, «Epopeyas postmodernas y topografías infernales sin salida», en José Manuel Losada y Antonella Lipscomb (eds.), Myth and Emotions (Cambridge, Cambridge Scholars Publishing, 2017), pp. 279-290.

HaSAn Sürcü, Delil, Voyeuristic Pleasure in Cinema: A Study of Voyeurism in Peeping Tom, Rear Window (Tesis de Máster, Aalborg, Aalborg University, 2017). Disponible en: <https://projekter.aau.dk/projekter/files/259994358/Full_PDF.pdf> (12/05/2020).

HERRERA, Javier, «El cine dentro del cine en la obra de Pedro Almodóvar: pasión cinéfila y tradición barroca», en María R. Matz y Carole Salmon (eds.), How the Films of Pedro Almodovar Draw upon and Influence Spanish Society (Nueva York, The Edwin Mellen Press, 2012), pp. 115-136.

Holtsmark, Erling B., «The Katabasis Theme in Modern Cinema», en Marti M. Winkler (ed.), Classical Myth and Culture in the Cinema (Oxford, Oxford University Press, 2001), pp. 23-50.

JARMUSCH, Jim, «Things I’ve learned: Jim Jarmusch» (Moviemaker Magazine, 5 de junio de 2013). Disponible en: <https://www.moviemaker.com/archives/series/things_ learned/jim-jarmusch-5-golden-rules-of-moviemaking/> (12/05/2020).

KrIsteva, Julia, «Word, Dialogue and Novel», en Toril Moi (ed.), The Kristeva Reader (Nueva York, Columbia University Press, 1986), pp. 34-61.

LaIng, Olivia, La ciudad solitaria. Aventuras en el arte de estar solo (Madrid, Capitán Swing, 2017).

MARINKovich, Juana, «El análisis del discurso y la intertextualidad» (Boletín de Filología de la Universidad de Chile, n. ${ }^{\circ}$ 37, 1998-1999), pp. 729-742.

PARdo García, Pedro Javier, «De la transescritura a la transmedialidad: poética de la ficción transmedial», en Antonio Gil González y Pedro Javier Pardo (eds.). Adaptación 2.o. Estudios comparados sobre intermedialidad. In honorem José Antonio Pérez Bowie (Binges, Éditions Orbis Tertius, 2018), pp. 41-92.

-, «Hacia una teoría de la reflexividad fílmica. La autoconciencia de la literatura al cine», en José Antonio Pérez Bowie y Pedro Javier Pardo García (eds.), Transescrituras audiovisuales (Madrid, Pigmalión, 2015), pp. 47-94.

-, «Teoría y práctica de la reescritura filmoliteraria (A propósito de las reescrituras de The Turn of the Screw)», en José Antonio Pérez Bowie (ed.), Reescrituras filmicas. Nuevos territorios de la adaptación (Salamanca, Universidad, 2010), pp. 45-102.

Pérez Bowie, José Antonio (ed.), Reescrituras filmicas. Nuevos territorios de la adaptación (Salamanca, Universidad, 2010). 
-, «Sobre reescritura y nociones conexas. Un estado de la cuestión», en José Antonio Pérez Bowie (ed.), Reescrituras fílmicas: nuevos territorios de la adaptación (Salamanca, Universidad, 2010), pp. 21-43.

-, «Cine e Intertextualidad», en José Antonio Pérez Bowie (ed.), Leer el cine. La teoría literaria en la teoría cinematográfica (Salamanca: Universidad, 2008), pp. 151167.

—, «La intertextualidad pictórica», en José Antonio Pérez Bowie (ed.), Leer el cine. La teoría literaria en la teoría cinematográfica (Salamanca: Universidad, 2008), pp. 163-167.

-, «El cine en, desde y sobre el cine: metaficción, reflexividad e intertextualidad en la pantalla» (Anthropos, n. ${ }^{\circ}$ 208, «Metaliteratura y metaficción. Balance crítico y perspectivas comparadas», 2005), pp. 122-137.

REQuena, Jesús G., «Viendo mirar (La mirada y el punto de vista en el cine de Hitchcock)», en Javier Luengos (ed.), Alfred Hitchcock (Oviedo, Fundación Municipal de Cultura, 1989), pp. 148-163.

Romero Escrivá, Rebeca, «El universo Psycho. "La ansiedad de la influencia” en la obra de Hitchcock» (L'Atalante. Revista de estudios cinematográficos, $\mathrm{n}^{\circ}{ }^{\circ} 18,2014$ ), pp. 64-70.

SANABRIA, Carolina, Contemplación de lo íntimo. Lo audiovisual en la cultura contemporánea (Madrid, Biblioteca Nueva, 2011).

SAnz CABrerizo, Amelia, «La noción de intertextualidad hoy» (Revista de Literatura, $\mathrm{n}^{0}$ 57, vol. 114, 1995), pp. 341-362.

Stam, Robert, «Introduction: The Theory and Practice of Adaptation», en Robert Stam y Alessandra Raengo (eds.), Literature and Film. A Guide to the Theory and Practice of Film Adaptation (Malden/Oxford, Blackwell Publishing, 2005), pp. 1-52, pp. 2631 de la traducción española Teoría y práctica de la adaptación (México, UNAM, 2014).

-, Film Theory. An Introduction (Malden/Oxford, Blackwell Publishing, 2000).

Tóтн, Erik, Intertextuality in the Cinematic Production of Quentin Tarantino (Tesis de Grado, Masaryk University, 2011). Disponible en: <https://is.muni.cz/th/m9mj2/ Thesis_Final.pdf > (12/05/2020).

\section{Filmografía}

American Psycho (Mary Harron, 2000). Estados Unidos: Shamley Productions.

A la caza (Cruising, William Friedkin, 1980). Estados Unidos/Alemania Occidental: Lorimar Film Entertainment/CiP-Europaische Treuhand AG.

Blade Runner (Ridley Scott, 1982). Estados Unidos: The Ladd Company/Shaw Brothers. El amor (L'amore, Roberto Rossellini, 1948). Italia: Tevere Films.

Gimme Shelter (Albert Maysles, David Maysles y Charlotte Zwerin, 1970). Estados Unidos: Maysles Films.

La delgada línea roja (The Thin Red Line, Terrence Malick, 1988). Estados Unidos: Fox 2000 Pictures/Geisler-Roberdeau Phoenix Pictures.

La matanza de Texas (The Texas Chain Saw Massacre, Tobe Hopper, 1974). Estados Unidos: Vortex.

La ventana indiscreta (Rear Window, Alfred Hitchcock, 1954). Estados Unidos: Patron INC. 
Metropolis (Fritz Lang, 1927). República de Weimar: UFA.

New York, New York (Martin Scorsese, 1978). Estados Unidos: Chartoff-Winkler Productions.

Psicosis (Psycho, Alfred Hitchcock, 1960). Estados Unidos: Shamley Productions.

Shame (Steve McQueen, 2011). Reino Unido: Film4/See-Saw Films/UK Film Council.

Recibido: 13 de septiembre de 2019

Aceptado para revisión por pares: 26 de febrero de 2020

Aceptado para publicación: 3 de mayo de 2020 
